Article

\title{
Solid-State Polymerization of Poly(Ethylene Furanoate) Biobased Polyester, III: Extended Study on Effect of Catalyst Type on Molecular Weight Increase
}

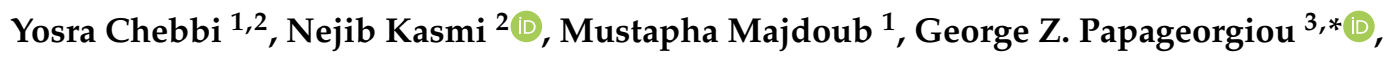 \\ Dimitris S. Achilias ${ }^{2}\left(\right.$ and Dimitrios N. Bikiaris ${ }^{2, *} *$ (i) \\ 1 Laboratoire des Interfaces et Matériaux Avancés, Université de Monastir, Monastir 5000, Tunisia; \\ yossrachebbi@gmail.com (Y.C.); mustaphamajdoub@gmail.com (M.M.) \\ 2 Laboratory of Polymer Chemistry and Technology, Department of Chemistry, Aristotle University of \\ Thessaloniki, GR-541 24 Thessaloniki, Greece; nejibkasmi@gmail.com (N.K.); axilias@chem.auth.gr (D.S.A.) \\ 3 Chemistry Department, University of Ioannina, P.O. Box 1186, 45110 Ioannina, Greece \\ * Correspondence: gzpap@cc.uoi.gr (G.Z.P.); dbic@chem.auth.gr (D.N.B.); \\ Tel.: +30-265-1008354 (G.Z.P.); +30-231-0997812 (D.N.B.)
}

Received: 6 February 2019; Accepted: 28 February 2019; Published: 6 March 2019

check for updates

\begin{abstract}
In this study, the synthesis of poly(ethylene furanoate) (PEF), catalyzed by five different catalysts-antimony acetate (III) (Sb Ac), zirconium (IV) isopropoxide isopropanal ( $\mathrm{Zr}$ Is Ip), antimony (III) oxide (Sb Ox), zirconium (IV) 2,4-pentanedionate ( $\mathrm{Zr} \mathrm{Pe}$ ) and germanium (IV) oxide (Ge Ox) — via an industrially common combination of melt polymerization and subsequent solid-state polymerization (SSP) is presented. In all reactions, proper amounts of 2,5-dimethylfuran-dicarboxylate (DMFD) and ethylene glycol (EG) in a molar ratio of $\mathrm{DMFD} / \mathrm{EG}=1 / 2$ and $400 \mathrm{ppm}$ of catalyst were used. Polyester samples were subjected to SSP procedure, under vacuum application, at different reaction times $(1,2,3.5$, and $5 \mathrm{~h})$ and temperatures of 190, 200, and $205^{\circ} \mathrm{C}$. Carboxyl end-groups concentration (-COOH), intrinsic viscosity (IV), and thermal properties, via differential scanning calorimetry (DSC), were measured for all resultant polymers to study the effect of the used catalysts on the molecular weight increase of PEF during SSP process. As was expected, it was found that with increasing the SSP time and temperature, the intrinsic viscosity and the average molecular weight of PEF steadily increased. In contrast, the number of carboxyl end-groups content showed the opposite trend as intrinsic viscosity, that is, gradually decreasing during SSP time and temperature increase. It is worthy to note that thanks to the SSP process an obvious and continuous enhancement in the thermal properties of the prepared PEF samples was attained, in which their melting temperatures $\left(T_{m}\right)$ and degree of crystallinity $\left(X_{\mathrm{c}}\right)$ increase progressively with increasing of reaction time and temperature. To predict the time evolution of polymers IV, as well as the hydroxyl and carboxyl content of PEF polyesters during the SSP, a simple kinetic model was developed. From both the theoretical simulation results and the experimental measurements, it was demonstrated that surely the $\mathrm{Zr}$ Is Ip catalyst shows the best catalytic characteristics compared to all other used catalysts herein, that is, leading in reducing-in a spectacular way-the activation energy of the involved both transesterification and esterification reactions during SSP.
\end{abstract}

Keywords: poly(ethylene furanoate); solid-state polycondensation; catalysts; thermal properties; polyester 


\section{Introduction}

In recent years, the interest to develop biobased ecofriendly polymeric materials derived from biomass-instead of petroleum-based polymers-has emerged with renewed strength. The latter was stimulated by the global depletion of fossil fuel resources and fluctuations in oil prices, as well as serious environmental pollution [1-7]. Moreover, the USA and European legislative landscapes are changing in favor of renewable resource-based products against fossil-based ones [8,9]. In this context, and thanks to the rapid development of the chemical industry and the optimization of biorefining processes $[10,11]$, large-scale production of renewable resource-derived monomers has been developed in the last few years and are now widely used as starting building blocks for biobased polymers production [12-14]. Among them, 2,5-furandicarboxylic acid (FDCA), which is widely recognized as the promising biobased substitute to terephthalic acid (TPA) [15], and its large-scale production have been realized recently. Thanks to its special chemical structure, FDCA has been selected as one of the 12 top value-added chemicals by the US Department of Energy [16]. In fact, for the above-mentioned reasons, a paradigm shift has emerged towards synthesizing of different homopolymers derived from the renewable-based aromatic diacid monomer (FDCA) and several diols [17-27]. In this sense, FDCA is on the way of industrialization and commercialization by many international companies, including Corbion, Avantium, ADM, BASF, and DuPont [28]. This is due to its great potential in high-performance renewable polymers synthesis; thereby, they can be served as alternatives to their current commercial fossil-based analogs. As a relevant example of sustainable FDCA-based polymers from renewable resources, poly(ethylene furan dicarboxylate) (PEF), produced from either 2,5-furandicarboxylic acid (2,5-FDCA) or its dimethyl ester (DMFD) and ethylene glycol, is the most promising biobased polyester. The latter is a $100 \%$ renewable-based alternative to its commercial petrochemical counterpart, polyethylene terephthalate (PET) [15]. Extensive research has escalated towards PEF since the last decade, and its most relevant achievements and its historical progress have been intensively described in two recent extended reviews [29,30]. The most spotlighted member of furanoate polyesters family-PEF-is of significant and increased interest, owing to its pioneering features and its entirely renewable source. This is clearly evident from the exhaustive and intensive studies, which have been conducted on this commercial polyester. Notably, outstanding properties of PEF polyester were revealed, such as greatly improved thermal stability up to $320^{\circ} \mathrm{C}$ [31,32], a superior barrier performance, where an impressive 19-fold and 10-27-fold reduction has been reported in $\mathrm{CO}_{2}$ and $\mathrm{O}_{2}$ permeability, respectively, for PEF with respect to its oil-based counterpart PET [33]. Other appealing characteristics, including better greenhouse gas balance and reduced carbon footprint [34], excellent mechanical properties [35], in addition of an ability to formulate in fibers, films, and most bottles make PEF an appropriate commodity for ecopackaging applications, and thereby it can serve as a promising substituent for PET in the near future [36]. Recently, the techno-economic feasibility of biorefinery to adopt biobased PEF polyester production has been definitely proven. In this context, as a result of all its unique aforementioned features, manufacturing of PEF has been begun in 2010 by Avantium in Netherlands for typical applications such as fibers, films, and in particular for packaging of alcoholic beverages, water, and soft drinks, among others, using the Avantium's YXY technology [37]. This is considered a key point in favor of this promising polyester, that is, it has now enabled prospects for its industrial-scale production, hence creating its own market.

Although much work has recently appeared on PEF by highlighting on its better features compared with its analog, PET, this promising polyester suffers from some drawbacks, which renders its industrialization process uneconomical. Particularly, production at high molecular weight PEF, which ensures the safe processing of the resulting polyester without any deterioration of its mechanical properties, besides overcoming of its high brittleness [38] and undesired yellow discoloration [39], is a challenge for both academic and industrial communities. The catalyst type used, which has an important role in molecular weight increase, as well as the decomposition of 2,5-FDCA at high reaction temperature during melt polycondensation reactions, are deemed to become one of the main causes to produce PEF with low molecular weight. 
Little research has been devoted to PEF synthesis, which involves studying the effect of different experimental conditions during the two-stage melt polycondensation process on its molecular weight increase. In this respect, Gruter et al. [40] claimed the synthesis of PEF via melt polycondensation using two catalysts: titanium (IV) Isopropoxide and a butyltin (IV) tris(octoate)-tris(nonylphenyl)phosphite mixed catalyst system. This systematic study was carried out on small scale in polycondensation films reactors. The authors reported that no increase in molecular weight was detected using a concentration of the first catalyst over $0.4 \mu \mathrm{mol}$, while a higher concentration of the second catalyst system leads to higher $M_{n}$. Moreover, results revealed that the addition of tris(nonylphenyl)phosphite may serve as a heat stabilizer, to reduce, significantly, the coloration of the obtained polyester, PEF. This assessment has mainly tackled the discoloration of PEF polyester by varying the used catalyst type.

To get high molecular weight polyesters with enhanced properties suitable for several applications (e.g., films, bottles, and fiber production), a well-known technique and extensively exploited in the industry as a third-step to polyesters, which is solid-state polymerization (SSP) [41]. This method is carried out by heating the partially crystalline polymer at a temperature between its glass transition temperature $\left(T_{\mathrm{g}}\right)$ and its melting point $\left(T_{\mathrm{m}}\right)$. The latter is greatly used for PET manufacturing to overcome its low molecular weight [42-49]. This postcondensation technique is ideally attractive and environmentally sound process compared to conventional melt polycondensation, as it is a solvent-free method and no toxic wastes are released upon its execution. Furthermore, as one of its most outstanding features, SSP requires uncomplicated and inexpensive equipment, as well as it can be implemented under relatively mild conditions, thereby fewer side reactions and thermal degradation can occur.

PEF is intriguing to both the scientific and industrial communities and it has drawn a keen interest as biobased polymer in food and beverage packaging. Much work has been dedicated to PEF investigation, showing thus the major advances and breakthroughs in this topic. In this context, significant number of studies addressed on its barrier [36,50-52], thermal [31,33,53-55], and mechanical $[35,56]$ properties, as well as investigations have dealt with the biaxial orientation [57], kinetics and dynamics of crystallization [58-61], synthesis, and structural characterization of this promising polyester $[24,54,62-66]$.

Apart from several studies recently published which expanded PEF polyester's properties panorama, only a few investigations exclusively dealt with the industrially relevant technique (SSP) of PEF, despite its benefits with respect to the manufacturing of high molecular weight polyester. To date, as far as we know, only three earlier appraisals [15,67,68], along with our previous studies [69-71], recently published, have been intended to investigate SSP of PEF as a subsequent third stage after two-step melt polycondensation procedure. In this regard, Knoop et al. [56] point out that the high molecular weight of PEF polyester was successfully achieved by applying SSP procedure under reduced pressure, using Ti(IV)-isopropoxide as catalyst. In this study, the synthetic challenge of high PEF polyester degree of polymerization was accomplished during several hours, in which the $M_{n}$ of the obtained polymer was gradually increased from $25,000 \mathrm{~g} / \mathrm{mol}$ to $83,000 \mathrm{~g} / \mathrm{mol}$ after 24 and $72 \mathrm{~h} \mathrm{SSP}$, respectively, at $180^{\circ} \mathrm{C}$. In fact, the crystallization investigation, as well as its influence on the mechanical properties of high molecular weight polyester PEF, has been evaluated thoroughly by the authors of this contribution. In the same vein, as reported in Hong's work [67], PEF has been subjected to SSP, and results exhibited an increase in IV values of the polyester sample from 0.6 to 0.64 and $0.72 \mathrm{dL} / \mathrm{g}$ after 24 and $48 \mathrm{~h}$ of SSP reaction time, respectively.

As one of very limited studies reporting the effect of the catalyst type on molecular weight increase of poly(ethylene furanoate) using solid-state polymerization, the aim of this work was to study the feasibility of PEF SSP, using a series of catalysts-Antimony Acetate (III) (Sb Ac), Zirconium (IV) Isopropoxide Isopropanal (Zr Is Ip), Antimony (III) Oxide (Sb Ox), Zirconium (IV) 2,4-pentanedionate (Zr Pe), and Germanium (IV) Oxide (Ge Ox). The effect of the catalyst type, along with the influence of the temperature and reaction time on the molecular weight increase of the prepared polyester PEF, was investigated in detail using both experimental measurements and a simple kinetic theoretical 
model. Notwithstanding the increasing number of publications towards PEF study, to the best of our knowledge, such work, which has not yet been reported, is essential nowadays to enable large-scale industrial production and commercial applications of PEF.

\section{Experimental}

\subsection{Materials}

2,5-furan dicarboxylic acid (2,5-FDCA, purum 97\%), ethylene glycol (99.8\%), Antimony acetate (III) (Sb Ac, 99.99\%), Antimony (III) Oxide (Sb Ox, >99\%), Germanium (IV) oxide (Ge Ox, >99.99), Zirconium (IV) 2,4-Pentanedionate (Zr Pe, 97\%), and Zirconium(IV) Isopropoxide Isopropanal (Zr Is Ip, 99.9\%) catalysts were purchased from Aldrich Co. (Chemie GmbH, Unna, Germany). All other solvents and materials used were of analytical grade.

\subsection{Synthesis of 2,5-Dimethylfuran-dicarboxylate(DMFD)}

Dimethyl 2,5-dimethylfurandicarboxylate (DMFD) was prepared following the reported procedure [55]. Briefly, in a random flask $(500 \mathrm{~mL})$, a mixture of $15.6 \mathrm{~g}$ of 2,5-furandicarboxylic acid, $2 \mathrm{~mL}$ of concentrated sulfuric acid and $200 \mathrm{~mL}$ of anhydrous methanol and was refluxed for 5 hours. The excess of the methanol was distilled and then the solution was filtered via a disposable Teflon membrane filter (Chemie GmbH, Unna, Germany). Dimethyl ester was precipitated during filtration as white powder. After cooling, $100 \mathrm{~mL}$ of distilled water was added to the powder. During stirring, a solution of $\mathrm{Na}_{2} \mathrm{CO}_{3} 5 \% \mathrm{w} / v$ was added to neutralize partially the dispersion while $\mathrm{pH}$ was measured continuously. The white powder was collected by filtration and the solid was washed several times with distilled water and finally dried. The isolated dimethyl ester was recrystallized using a mixture of 50/50 v/v methanol/water, and white needles of DMFD were isolated in $83 \%$ yield. The melting point of the prepared DMFD herein is $109.6^{\circ} \mathrm{C}$. This is in good agreement with what was reported in a previous study of Knoop et al. [56] ( $\left.T_{\mathrm{m}}: 109.76^{\circ} \mathrm{C}\right)$.

\subsection{Polyester Synthesis}

PEF samples were synthesized through the two-step melt polycondensation (esterification and polycondensation) in a glass batch reactor following the same procedure reported in our previous work [72]. Briefly, predetermined amount of DMFD and ethylene glycol in a molar ratio of diester/diol $=1 / 2$ were charged with $400 \mathrm{ppm}$ of each catalyst relative to the amount of DMFD ( $\mathrm{Sb} \mathrm{Ac}, \mathrm{Sb} \mathrm{Ox}, \mathrm{Ge} \mathrm{Ox}, \mathrm{Zr} \mathrm{Pe}$, and $\mathrm{Zr}$ Is Ip) into the reaction tube of the polyesterification apparatus. In the first stage, the reaction mixture was heated under controlled $\mathrm{N}_{2}$ atmosphere for $2 \mathrm{~h}$ at $160{ }^{\circ} \mathrm{C}$, at $170{ }^{\circ} \mathrm{C}$ for an additional $1 \mathrm{~h}$, and finally it was left to proceed for $1 \mathrm{~h}$ at $180-190^{\circ} \mathrm{C}$. This first stage (transesterification) was considered complete after the collection of almost all the theoretical amount of $\mathrm{CH}_{3} \mathrm{OH}$, which was removed by distillation from the reaction mixture in a graduated cylinder. In the second polycondensation step, a high pressure of 5.0 Pa was gradually applied over a period of $30 \mathrm{~min}$ to remove the excess EG diol, to avoid excessive foaming and, moreover, to minimize oligomer sublimation, which presents a problem during the melt polycondensation. The reaction mixture was gradually raised to $230{ }^{\circ} \mathrm{C}$, while stirring speed was set at $720 \mathrm{rpm}$. The reaction was maintained at this temperature for $2 \mathrm{~h}$. After the polycondensation reaction was finished, PEF sample was easily removed from the reactor, milled, and washed with methanol.

\subsection{Solid-State Polycondensation}

Solid-state polymerization (SSP) was performed using a reaction apparatus involving five volumetric flasks $(100 \mathrm{~mL})$, which were connected to a vacuum line, and were immersed in a sodium nitrite/potassium nitrate thermostated bath, having a precision within $\pm 0.5 \mathrm{C} .2 \mathrm{~g}$ of crystallized PEF with a particle size of $-0.40+0.16 \mathrm{~mm}$ were introduced in each one of the volumetric flasks under vacuum, stabilized beneath 3 and $4 \mathrm{~Pa}$. The reaction temperature was maintained constant at 
190,200 or $205^{\circ} \mathrm{C}$. The flasks were withdrawn from the bath after $1,2,3.5$, and $5 \mathrm{~h}$ for analysis of the PEF samples' intrinsic viscosity (IV), to identify the molecular weight of the PEF polyester, as well as measuring the carboxyl end-group concentration $(\mathrm{COOH})$.

\subsection{Polyester Characterization}

\subsubsection{Intrinsic Viscosity Measurement}

For intrinsic viscosity [ $\eta$ ] measurements, a mixture of phenol/tetrachloroethane $(60: 40 w / w)$ was used to dissolve PEF samples $(1 \mathrm{wt} \%)$ at $90^{\circ} \mathrm{C}$. To achieve a complete dissolution, the latter were maintained under stirring in the above mixture of solvents at this temperature for $10 \mathrm{~min}$. After cooling to room temperature and filtration using a disposable membrane filter (Teflon) to eliminate any nonsoluble materials, their flow time was measured at $25^{\circ} \mathrm{C}$ using an Ubbelohde viscometer (Schott Gerate GMBH, Hofheim, Germany). The intrinsic viscosity [ $\eta$ ] of each PEF sample was calculated using the following Solomon-Ciuta equation.

$$
[\eta]=\left[2\left\{t / t_{0}-\ln \left(t / t_{0}\right)-1\right\}\right]^{1 / 2} / c
$$

where $t$ is the flow time of solution, $t_{0}$ is the flow of pure solvent, and $c$ is the concentration of the solution. For each sample, the average value was determined after performing three different measurements.

\subsubsection{Molecular weight}

The number average molecular weight $\left(\bar{M}_{n}\right)$ of the PEF samples was determined from the measured [ $\eta$ ] values, using the Berkowitz equation [73], as was modified in our previous report [74]:

$$
\bar{M}_{n}=3.29 \times 10^{4}[\eta]^{1.54}
$$

\subsubsection{End-Group Analysis}

Carboxyl end-group content (C.C.) of the PEF samples was determined according to Pohl's method by titrating a solution of the PEF in chloroform/alcohol mixture. A standard solution of $\mathrm{NaOH}$ in benzyl alcohol and phenol red as indicator was used [75]. For each sample, three different measurements have been done and the average C.C. value was calculated.

\subsubsection{Wide Angle X-Ray Diffraction Patterns (WAXD)}

X-ray diffraction measurements of the prepared PEF polyester samples with different catalysts before SSP, in the form of powder, were performed in the wide-angle region in the angle (2 $2 \theta)$ range from $5^{\circ}$ to $60^{\circ}$, at steps of $0.05^{\circ}$, and counting time of $5 \mathrm{~s} / \mathrm{step}$, using a MiniFlex II XRD system from Rigaku Co. (Tokyo, Japan) with CuK $\alpha$ radiation $(\lambda=0.154 \mathrm{~nm})$.

\subsubsection{Differential Scanning Calorimetry (DSC)}

Thermal analysis of PEF polyesters was carried out using a Perkin-Elmer, Pyris Diamond DSC differential scanning calorimeter (Perkin-Elmer, Waltham, MA, USA), calibrated with high purity metal standards (indium and zinc). For each measurement, a PEF sample of $6 \pm 0.1 \mathrm{mg}$ was placed in aluminum pan and was then heated from 30 to $250{ }^{\circ} \mathrm{C}$ at a scanning rate of $20{ }^{\circ} \mathrm{C} . \mathrm{min}^{-1}$ under $\mathrm{N}_{2}$ flow $(50 \mathrm{~mL} / \mathrm{min})$. The melting temperature $\left(T_{\mathrm{m}}\right)$, the glass transition temperature $\left(T_{\mathrm{g}}\right)$, and the heat fusion (DHm) of the PEF polyesters were measured from these scans. 


\section{Modeling the PEF SSP Kinetics}

\subsection{Reaction Mechanism}

The reactions occurring during SSP of PEF polyester include polycondensation/transesterification, esterification, thermal degradation, and side reactions of vinyl end-groups [43]. The latter are illustrated in the following Equations (3)-(6), in which $k_{1}, K_{1}$ and $k_{2}, K_{2}$ indicate the forward and equilibrium rate constants of transesterification and esterification reactions, respectively, while $k_{\mathrm{v}}$ and $k_{\mathrm{d}}$ refer to the kinetic rate constants of the polycondensation of vinyl end-groups and degradation reactions, which are considered one way. It should be pointed that the reverse kinetic rate constants $k_{1}{ }^{\prime}$ and $k_{2}{ }^{\prime}$ in Equations (3) and (4) have been replaced by their equivalent $k_{1}{ }^{\prime}=k_{1} / K_{1}$ and $k_{2}{ }^{\prime}=k_{2} / K_{2}$ from the definition of the equilibrium rate constants as, $K_{1}=k_{1} / k_{1}{ }^{\prime}$ and $K_{2}=k_{2} / k_{2}{ }^{\prime}$, respectively.

Polycondensation/transesterification

2<smiles>CC(=O)c1ccc(C(=O)OCCO)o1</smiles>

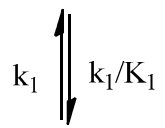<smiles>CC(=O)c1ccc(C(=O)OCCOC(=O)c2ccc(C(=O)[OH2+])o2)o1</smiles>

\section{Esterification}<smiles>[Y10]CC(C)C(=O)c1ccc(C(=O)OCCOC(=O)c2ccc(C(=O)OCCO)o2)o1</smiles> 
Thermal degradation<smiles>C=COC(=O)c1ccc(C(=O)OCCOC(=O)c2ccc(C(=O)OCCOC(=O)c3ccc(C(C)=O)o3)o2)o1</smiles>

Polycondensation of vinyl end-groups<smiles>C=COC(=O)c1ccc(C(=O)OCCOC(=O)c2ccc(C(=O)OCCOC(=O)c3ccc(C(C)=O)o3)o2)o1</smiles>

The molecular weight of the PEF polyester is increased by two reactions: the first one is polycondensation/transesterification (Equation (3)), where two hydroxyl end-groups react, and ethylene glycol was produced. The second reaction is the esterification (Equation (4)), in which a carboxyl end-group reacts with a hydroxyl, and $\mathrm{H}_{2} \mathrm{O}$ is released as by-product. In contrast, when thermal degradation occurs (Equation (5)), the molecular weight of the polymer can be decreased by an ester bond cleavage in the macromolecular chain, thereby generating a carboxyl end-group and a vinyl ester end-group. In addition, the vinyl ester end-group may take part in side reactions with a hydroxyl end-group, resulting in the molecular weight increase (Equation (6)). The overall reaction rate is influenced by a combination of intrinsic reaction kinetics, diffusional limitations of the reactive end-groups, change of polymer degree of crystallization, and of the desorbing volatile byproducts (i.e., water and glycol) [76].

\subsection{Simplified Mathematical Model}

The problem of modeling the SSP kinetics is quite complicated, since, besides chemical kinetics, describing the rate of change of the species' concentration as a function of time, diffusion phenomena should be included, which results in additional variation with the distance from the interface [43]. Thus, two independent variables are presented, resulting in a set of partial differential equations that must be solved, including several diffusional, kinetic, and crystallization parameters [77]. Adopting such complicated models to simulate a few experimental data points is out of any physical meaning. Since in this investigation, only five data points were measured at each experimental condition, a simple kinetic modeling approach was adopted after Agarwal et al. [78,79]. This approach was initially developed for the SSP of PET, and successfully applied by our research group in modeling the SSP of PEF with nanoadditives, as well as of PET with several nanoadditives [69,80-82].

The following assumptions were made in order to develop the mathematical model. 
- $\quad$ All kinetic rate constants are regarded independent of polymer chain length (only end-group reactivity is considered).

- The backward reactions in Equations (3) and (4) are eliminated. This is due to the very fast removal of the ethylene glycol and water produced in the reaction mixture, caused by the high vacuum application (beneath 3 and $4 \mathrm{~Pa}$ ).

- $\quad$ Since polycondensation occurs at relatively low temperatures (i.e., $190-205^{\circ} \mathrm{C}$ ), no side reactions for the formation of acetaldehyde or thermal degradation are considered (Equations (5) and (6) are excluded).

- Diffusional limitations on account of desorbing volatile species are ignored.

- $\quad$ Then, the rate of change of hydroxyl $([\mathrm{OH}])$ and carboxyl $([\mathrm{COOH}])$ end-groups can be described by the following expressions $[78,79]$.

$$
\begin{gathered}
\frac{d[\mathrm{OH}]_{t}}{d t}=-2 k_{1}[\mathrm{OH}]_{t}^{2}-k_{2}[\mathrm{COOH}]_{t}[\mathrm{OH}]_{t} \\
\frac{d[\mathrm{COOH}]_{t}}{d t}=-k_{2}[\mathrm{COOH}]_{t}[\mathrm{OH}]_{t}
\end{gathered}
$$

where $[\mathrm{COOH}]_{t}$ and $[\mathrm{OH}]_{t}$ denote the actual 'true' carboxyl and hydroxyl end-group concentration, respectively.

The term "actual hydroxyl and carboxyl end-groups" was introduced by Agarwal and coworkers [78,79], in order to account for the rapid slowdown in SSP kinetics at high [ $\eta]$ values. Accordingly, a part of the hydroxyl $([\mathrm{OH}])$ and carboxyl end-groups $([\mathrm{COOH}])$ were considered to be rendered temporarily inactive (denoted as $[\mathrm{OH}]_{i}$ and $[\mathrm{COOH}]_{i}$ ) and the actual concentration of $\mathrm{OH}$ and $\mathrm{COOH}$ in Equations (7) and (8) can be expressed as

$$
\begin{gathered}
{[\mathrm{OH}]_{t}=[\mathrm{OH}]-[\mathrm{OH}]_{i}} \\
{[\mathrm{COOH}]_{t}=[\mathrm{COOH}]-[\mathrm{COOH}]_{i}}
\end{gathered}
$$

where $[\mathrm{COOH}],[\mathrm{OH}]$ and $[\mathrm{COOH}]_{i},[\mathrm{OH}]_{i}$ denote the concentration of the total and temporarily inactivated $\mathrm{COOH}$ and $\mathrm{OH}$ end-groups, respectively.

Furthermore, the number average molecular weight can be expressed as

$$
\bar{M}_{n}=\frac{2}{[\mathrm{COOH}]+[\mathrm{OH}]}
$$

Then, Equations (7) and (8), together with Equations (2) and (9)-(11), constitute a set of ordinary differential equations which can be readily solved numerically using varying step-size Runge-Kutta method, to give results on the variation of the intrinsic viscosity and the concentration of carboxyl and hydroxyl end-groups as a function of time. Four adjustable parameters- $[\mathrm{OH}]_{i},[\mathrm{COOH}]_{i}, k_{1}$, and $k_{2}$-are estimated at each experimental condition by simultaneous fitting of the values of all the three variables ( $\mathrm{IV},[\mathrm{OH}]$, and $[\mathrm{COOH}])$ to the experimental data points as a function of time.

\section{Results and Discussion}

In this work, emphasis is given to study the effect of five different catalysts, namely Ge Ox, $\mathrm{Zr}$ Is $\mathrm{Ip}, \mathrm{Sb} \mathrm{Ac}, \mathrm{Sb} \mathrm{Ox}$, and $\mathrm{Zr}$ Pe, on solid-state polymerization (SSP) of PEF. The latter were first synthesized by melt polycondensation according to our previous work [83] and their intrinsic viscosities oscillate between 0.25 and $0.40 \mathrm{dL} / \mathrm{g}$. X-ray diffraction analysis (WAXD) was conducted to assess the crystalline structure of the resulting PEF materials after melt polycondensation. As can be seen from Figure 1, only PEF polyesters prepared with ( $\mathrm{Sb} \mathrm{Ac}$ ) and ( $\mathrm{Zr}$ Is Ip) catalysts are completely amorphous, while the diffractogram of the other three samples proves their semicrystalline nature, all exhibiting very similar diffraction peaks at $16.1^{\circ}, 17.7^{\circ}, 19.1^{\circ}, 20.4^{\circ}, 23.3^{\circ}$, and $26.6^{\circ}$, as stated in our earlier reports $[33,84]$. This finding confirms that the crystallinity of PEF depends on the used catalyst type. After melt 
polycondensation, SSP was carried out under vacuum at different temperatures $\left(190,200\right.$, and $\left.205^{\circ} \mathrm{C}\right)$ for $1,2,3.5$, and $5 \mathrm{~h}$. Polyesters samples for SSP should be crystallized at $170{ }^{\circ} \mathrm{C}$ for $6 \mathrm{~h}$ before SSP. This step, used always in PET before SSP, is mandatory to avoid any PEF amorphous regions that stuck each other.

\subsection{Kinetic Study of the Solid-State Polymerization of PEF}

SSP is an important process widely applied after melt polymerization to improve the mechanical and rheological properties of polymers. Therefore, it is also a common approach to overcome its low molecular weight. The current work is a continuation of a study of the temperature and time evolution during SSP on polymer's hydroxyl and carboxyl content as well as the intrinsic viscosity.

SSP was carried out at temperatures 190,200 and $205^{\circ} \mathrm{C}$ for $1,2,3.5$, and $5 \mathrm{~h}$. Figure 2 shows the effect of time and temperature during solid-state polymerization on the variation of the intrinsic viscosity with time for all the polyesters samples investigated. As it can be seen, regardless of the type of catalyst used, with increasing time or temperature, the intrinsic viscosity significantly increases, for example, for $\mathrm{PEF} / \mathrm{Zr} \mathrm{Pe}$, the intrinsic viscosity starts from $0.38 \mathrm{dL} / \mathrm{g}$ to achieve after $5 \mathrm{~h}$ of polycondensation $0.43 \mathrm{dL} / \mathrm{g}$ at $190^{\circ} \mathrm{C}$ or $0.54 \mathrm{dL} / \mathrm{g}$ at $205^{\circ} \mathrm{C}$. Using Ge Ox as catalyst, the intrinsic viscosity increased from $0.28 \mathrm{dL} / \mathrm{g}$, to $0.41,0.43$, and $0.49 \mathrm{dL} / \mathrm{g}$ after $5 \mathrm{~h}$ of solid-state polycondensation respectively at 190,200 , and $205^{\circ} \mathrm{C}$. The use of this catalyst during SSP results in a polymer having the lowest intrinsic viscosity; whereas, the IV of PEF when using Zr Is Ip was the highest. In the latter case, IV starts from $0.47 \mathrm{dL} / \mathrm{g}$ at $190^{\circ} \mathrm{C}$ to reach $0.60 \mathrm{dL} / \mathrm{g}$ after $5 \mathrm{~h}$ at $205^{\circ} \mathrm{C}$. Using Sb Ox, at $190^{\circ} \mathrm{C}$ the IV was $0.33 \mathrm{dL} / \mathrm{g}$, and increased progressively with temperature during time to achieve after $5 \mathrm{~h}$ at $205^{\circ} \mathrm{C}$ the value of $0.51 \mathrm{dL} / \mathrm{g}$. For PEF/Sb Ac, an increasing intrinsic viscosity was observed, starting from $0.37 \mathrm{dL} / \mathrm{g}$ to reach $0.52 \mathrm{dL} / \mathrm{g}$ after $5 \mathrm{~h}$ at $205^{\circ} \mathrm{C}$. As it was expected, during SSP, which is performed in the crystalline state of the polyesters, the concentration of the polymer chain and the mobility of the end-group was consequently enhanced, this is certainly due to increasing of the end-groups reactivity and the concomitant diffusion of diol which leads to chain extension. However, the study of intrinsic viscosity values affords a general idea about the activity of each catalyst; thus, at $190^{\circ} \mathrm{C}$, the evolution during time of the intrinsic viscosities was very leisurely despite the type of catalyst. This is was expected because the esterification and transesterification reactions were very low at this temperature, which is $20-30{ }^{\circ} \mathrm{C}$ below the melting point of PEF. Overall, those reactions are controlled by the diffusion of two products (water and ethylene glycol), with the latter became tardy at low SSP temperature. For the same reasons, an increasing of the IV values was distinguished at $200{ }^{\circ} \mathrm{C}$. However, at $205^{\circ} \mathrm{C}$, which is closer to the melting point of PEF, whatever the catalyst used, we noticed during the first two hours a rapid increase of the IV. As a consequence of this high temperature, it becomes more straightforward for the hydroxyl and carboxyl end-groups to react together because of the higher mobility of the macromolecular chains of PEF; which consequently enhances the molecular weight of the polyester. Based on what has been discussed above about the IV variation, we can conclude that the temperature is one of the most important parameters which could affect the molecular weight of the polymer. The number average molecular weight $\left(M_{n}\right)$ of all synthesized PEF and the corresponding number average of the degree of polymerization are presented in Table 1. These values were estimated from the experimental data of IV using Equation (2). As it was anticipated, $M_{\mathrm{n}}$, such as IV, depends on time and temperature. It is noteworthy that all the values may not be precise since in literature Equation (2) is available for PET. However, from this data, it seems that using Zr Is Ip leads to a PEF polyester with higher molecular weight than the other catalysts used previously even higher than PEF with DBTO, TBT and TIS as it was found in our previous work [70]. In contrast, Ge Ox catalyst led to the lowest $M_{\mathrm{n}}$ values. 
Table 1. Number average molecular weights $\left(\bar{M}_{n}, \mathrm{~g} / \mathrm{mol}\right)$ of PEF polyester using different catalysts obtained after SSP at different temperatures and times. The value included in parenthesis is the corresponding number average degree of polymerization.

\begin{tabular}{ccccccc}
\hline Temperature $\left({ }^{\circ} \mathbf{C}\right)$ & SSP Time (h) & PEF/Sb Ac & PEF/Ge Ox & PEF/Sb Ox & PEF/Zr Is Ip & PEF/Zr Pe \\
\hline & 0 & $4000(21)$ & $4600(25)$ & $5700(31)$ & $8000(44)$ & $5000(27)$ \\
\hline \multirow{3}{*}{190} & 1 & $7100(39)$ & $4600(25)$ & $6000(33)$ & $10300(57)$ & $7400(41)$ \\
& 2 & $7400(41)$ & $5700(31)$ & $7400(41)$ & $11300(62)$ & $8300(46)$ \\
& 3.5 & $7700(42)$ & $6800(37)$ & $8000(44)$ & $12400(68)$ & $8600(48)$ \\
& 5 & $9300(51)$ & $8300(46)$ & $8300(46)$ & $13100(81$ & $9000(49)$ \\
\hline \multirow{2}{*}{200} & 1 & $7700(42)$ & $5400(30)$ & $7700(42)$ & $10300(57)$ & $10300(57)$ \\
& 2 & $9000(49)$ & $6500(36)$ & $8000(44)$ & $12400(68)$ & $11300(62)$ \\
& 3.5 & $10300(57)$ & $8000(44)$ & $8600(48)$ & $13800(76)$ & $12000(66)$ \\
205 & 5 & $11000(60)$ & $9000(49)$ & $10000(55)$ & $14400(79)$ & $12400(68)$ \\
\hline & 1 & $9000(49)$ & $6800(37)$ & $9300(51)$ & $12000(66)$ & $11000(60)$ \\
& 2 & $10000(55)$ & $9600(53)$ & $9600(53)$ & $13500(74)$ & $12000(66)$ \\
& 3.5 & $10600(58)$ & $10600(58)$ & $10300(57)$ & $15000(82)$ & $12400(68)$ \\
& 5 & $12000(66)$ & $11000(60)$ & $11700(64)$ & $15800(86)$ & $12700(70)$ \\
\hline
\end{tabular}

The second parameter used to illuminate the effect of SSP time and temperature is the carboxyl end-group analysis $(-\mathrm{COOH})$ which is performed on all PEF samples. Figure 3 displays the variation of the end-group concentration during time when the catalyst and the temperature are modified. It is noteworthy that, regardless the type of catalyst used, all PEF polyesters have a small amount of carboxyl end-groups. According to the literature, the determined carboxyl end-groups for neat PEF was ( $36 \mathrm{eq} / 10^{6} \mathrm{~g}$ ). As it can be seen from the experimental curves, at temperatures close to the melting point of PEF, the trend is even more obvious, it shows the fastest decrease no matter which catalyst we use. However, for PEF using Ge Ox, Sb Ac, and Sb Ox the carboxyl end-groups starts approximately at $205^{\circ} \mathrm{C}$ from 25 to reach $15 \mathrm{eq} / 10^{6} \mathrm{~g}$ after 5 hours. Using $\mathrm{Zr}$ Is Ip as a catalyst, which provides the highest molecular weight of PEF, the carboxyl end-groups at $205^{\circ} \mathrm{C}$ begin at 51 to attain, after $5 \mathrm{~h}$ of SSP, $22 \mathrm{eq} / 10^{6} \mathrm{~g}$, whereas the concentration of the carboxyl end-groups for PEF with $\mathrm{Zr}$ Pe was reduced to $7.38 \mathrm{eq} / 10^{6} \mathrm{~g}$ at $205^{\circ} \mathrm{C}$ after 5 hours. After a general inspection about the evolution of the carboxyl end-groups values, it is notable that the latter depend essentially on time, thus with increasing time it was continuously reduced, whereas with increasing temperature the variation was less important. As it can be seen from Figure 3, this reduction was more important at $205^{\circ} \mathrm{C}$ wherein the deviation angle of curves during time was more important, whereas at 200 and $190^{\circ} \mathrm{C}$ it was less sharp and almost linear. All PEF polyesters were performed via the two-step melt polycondensation thus the bis-hydroxyethylene furanoate formed at the first stage was conducted to a second stage of polycondensation in order to prepare poly(ethylene furanoate) which contain as end-groups only hydroxyl. The existence of the carboxyl end-groups can be elucidated by the existence of decomposition reactions that are taken place during melt polycondensation which lead to carboxyl and vinyl end-groups (Equation (5)). According to Wang et al. [45], another amount of carboxyl end-groups could be acquired because of the reaction of esterification taking place (Equation (4)); therefore, the molecular weight of PET also was enhanced while the carboxyl end-groups was decreased because of the reaction of esterification taking place.

Moreover, hydroxyl end-groups content (-OH) for all PEF polyesters using different catalysts was calculated and presented in Figure 4a-e. As it was anticipated, the hydroxyl contents were reduced with increasing time and temperature during SSP, therefore, at higher SSP temperature $\left(205^{\circ} \mathrm{C}\right)$, the slowdown was the most important. The diagrams show a rapid decrease in the calculated $-\mathrm{OH}$ content during the first $2 \mathrm{~h}$ for all PEF polyesters regardless the type of catalyst. Afterwards, it becomes less important. This variation is in well agreement with the corresponding IV values, thus the latter shows an important increase during the first $2 \mathrm{~h}$ which leads to an important increase on the $M_{n}$. At all times and temperatures investigated during SSP, the final PEF/Ge Ox polyesters exhibit 
the highest hydroxyl end-groups values $\left(171.33 \mathrm{eq} / 10^{6}\right)$ while PEF/Zr Is Ip displayed the lowest one $\left(111.11 \mathrm{eq} / 10^{6}\right)$. This is most likely due to the difference in the reactivity of the catalysts. Finally, using $\mathrm{Sb}$ Ac as a catalyst, PEF polyesters produced have the highest rate of inactive hydroxyl end-group, so it can be stated that this catalyst is the most active compared to the other four catalysts.

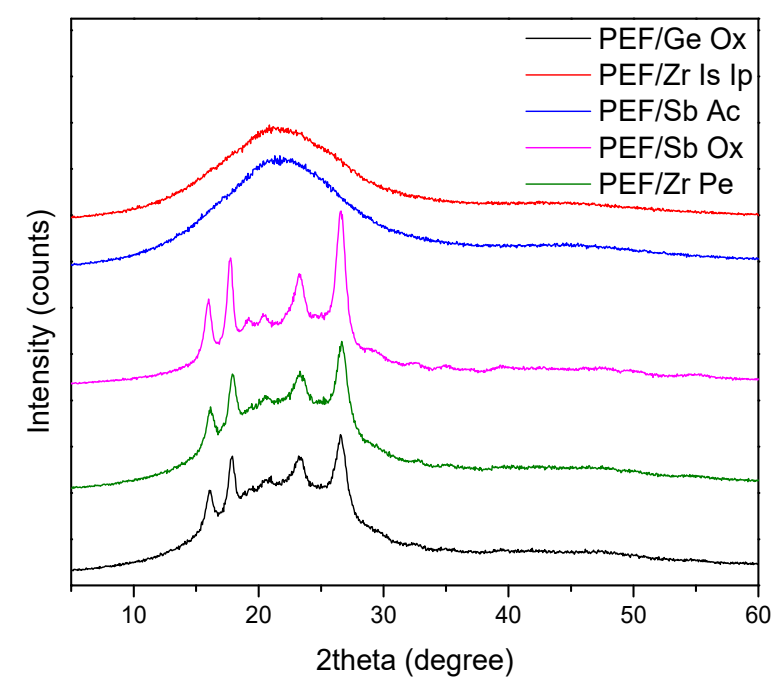

Figure 1. X-ray diffraction analysis (WAXD) patterns of as received poly(ethylene furanoate) (PEF) samples after melt polycondensation using five different catalysts (Ge Ox, Zr Is Ip, Sb Ac, Sb Ox, and Zr Pe).
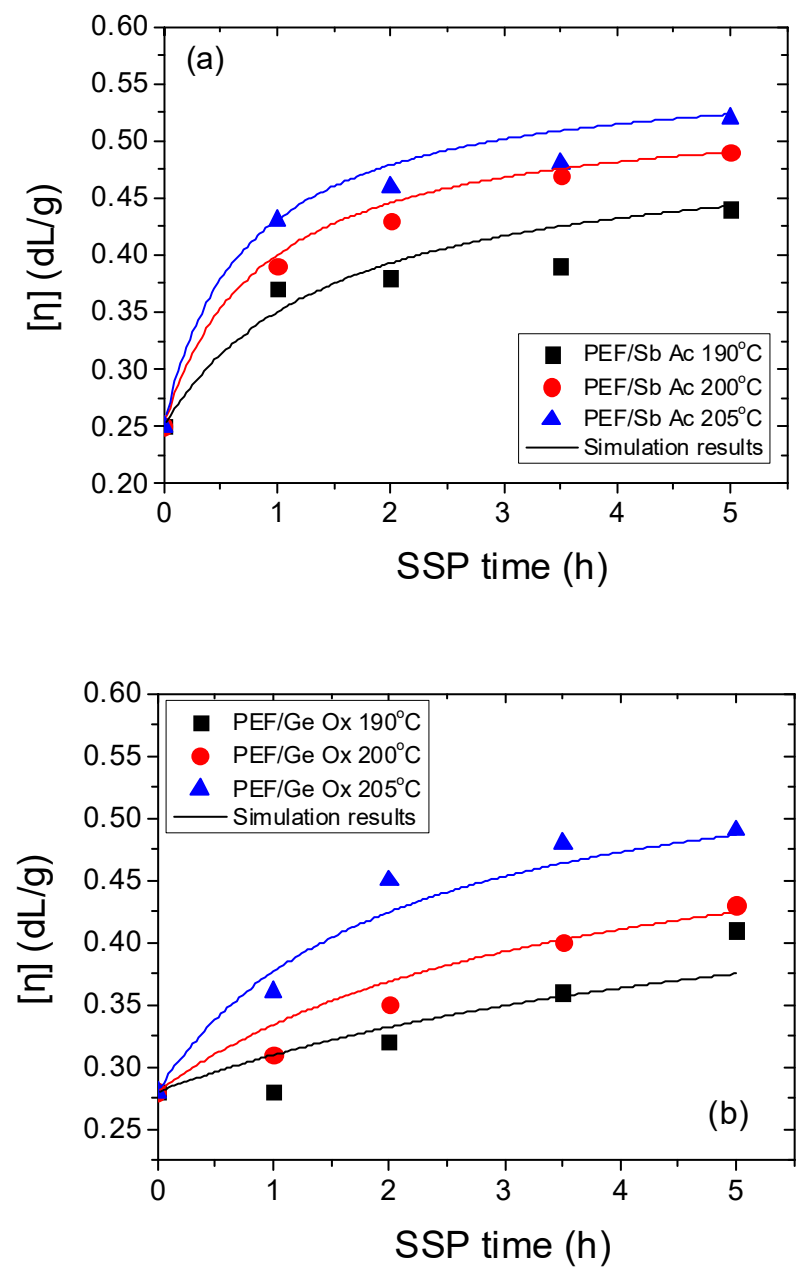

Figure 2. Cont. 

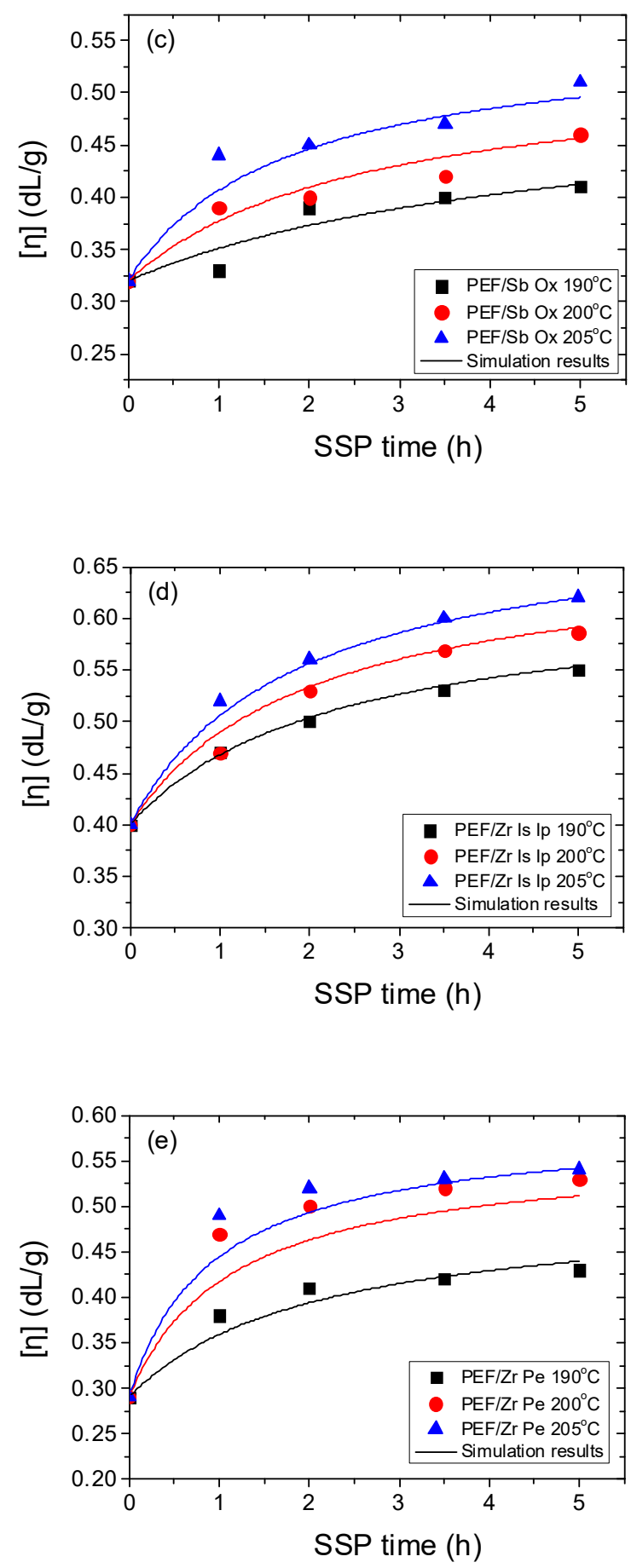

Figure 2. Variation of the intrinsic viscosity with time during the solid-state polymerization (SSP) of PEF using different catalysts—Sb Ac (a), Ge Ox (b), Sb Ox (c), Zr Is Ip (d), and Zr Pe (e)—at different temperatures. Continuous lines represent the theoretical kinetic model simulation results. 

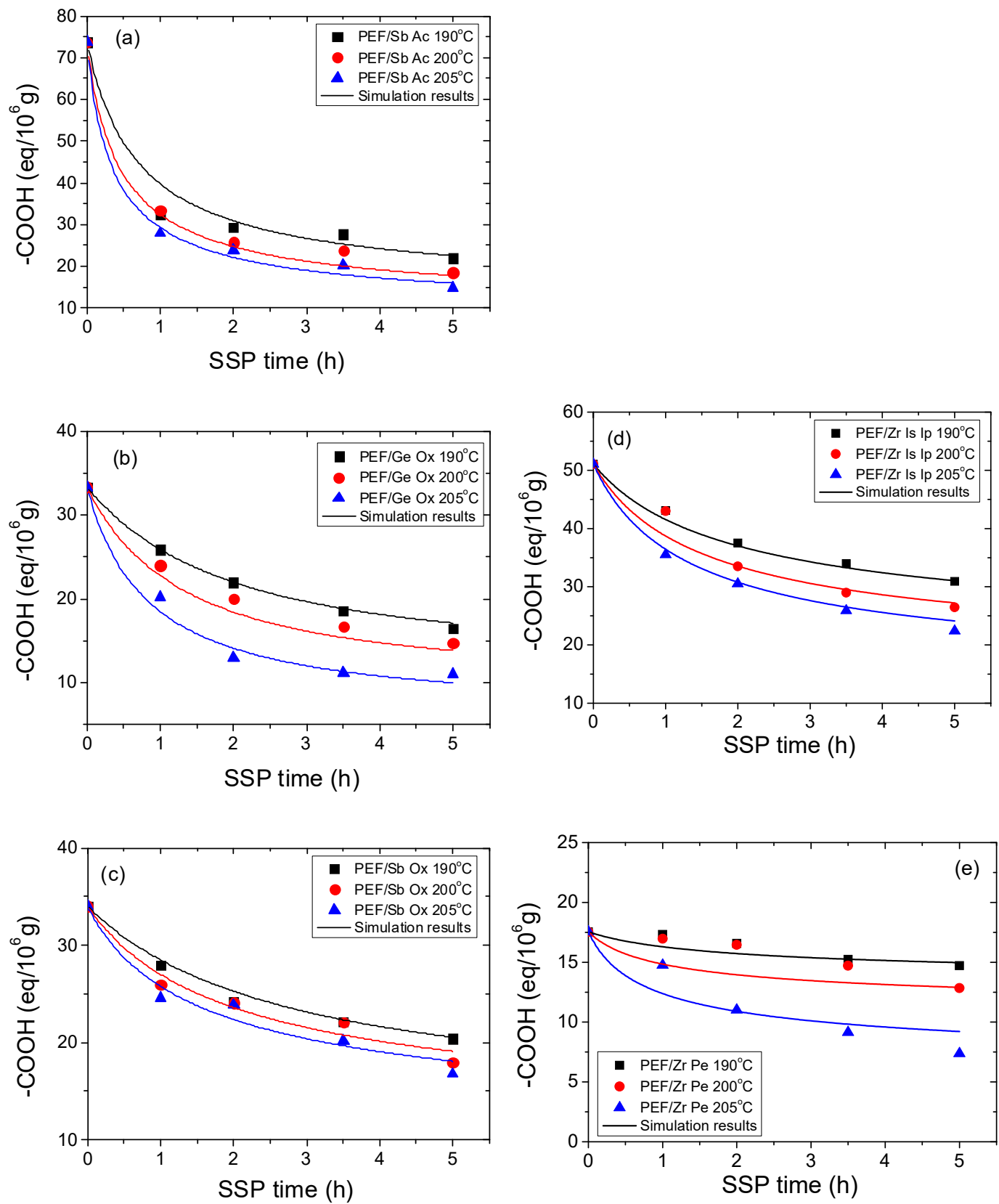

Figure 3. (-COOH) Variation with time during SSP: PEF/Sb Ac (a), PEF/Ge Ox (b), PEF/Sb Ox (c), PEF/Zr Is Ip (d), and PEF/Zr Pe (e) at different temperatures. Continuous lines represent the theoretical kinetic model simulation results.

Furthermore, the theoretical kinetic model presented in Section 3 was employed in order to estimate the kinetic rate constants of the esterification and polycondensation reactions, $k_{2}$ and $k_{1}$, respectively. Differential equations (7) and (8) were solved numerically together with Equations (2), (9)-(11), and IV values, as well as the concentration of hydroxyl and carboxyl end-groups that were obtained as a function of SSP time. The parameters $k_{1}, k_{2},[\mathrm{OH}]_{\mathrm{I}}$, and $[\mathrm{COOH}]_{\mathrm{i}}$ were calculated from fitting to the experimental data presented in Figures 1-3 for all PEF samples at all temperatures and times. Optimized values are illustrated in Table 2 and plotted as a function of temperature in Figure 5. Results of the theoretical simulation curves are included as continuous lines in the above-mentioned figures. As it can be seen, theoretical simulation curves satisfactorily follow the experimental data at all different temperatures. Discrepancies could be attributed to the assumptions made, when developing the simple kinetic model. 

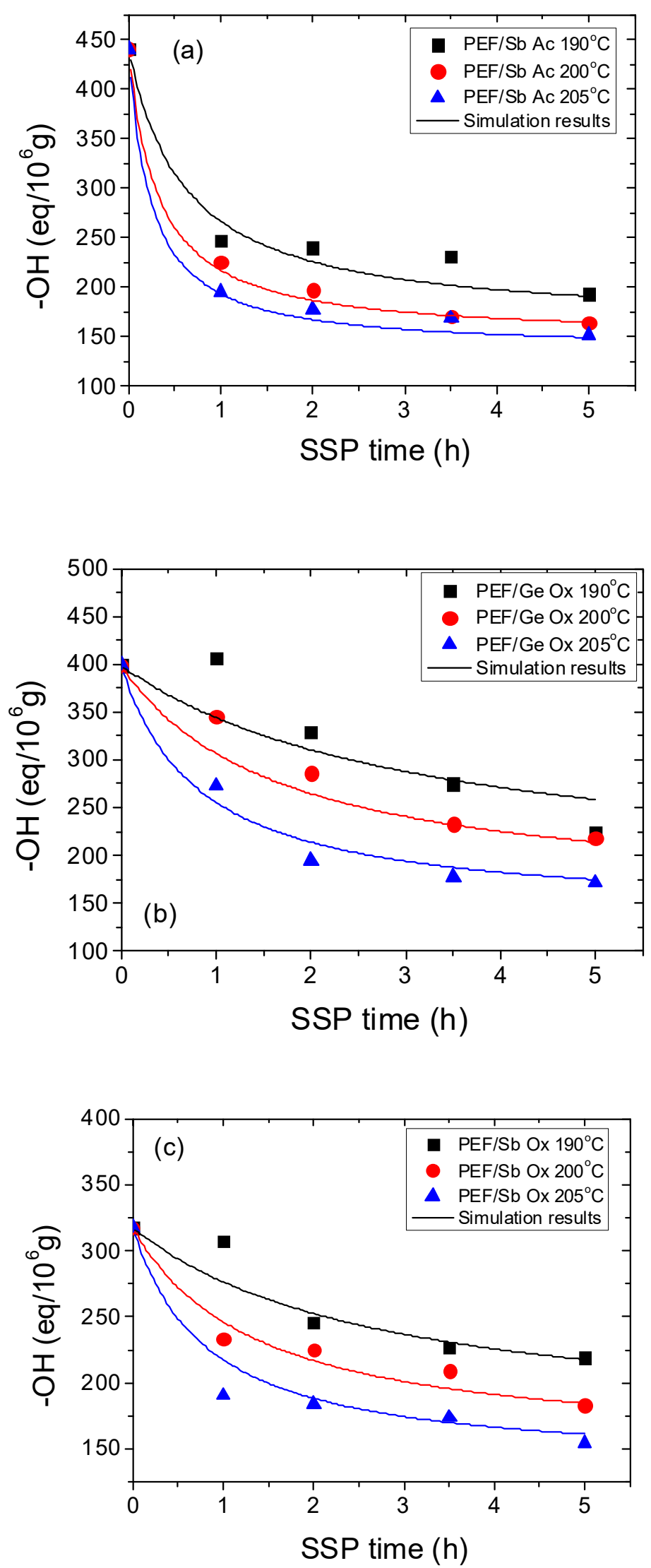

Figure 4. Cont. 

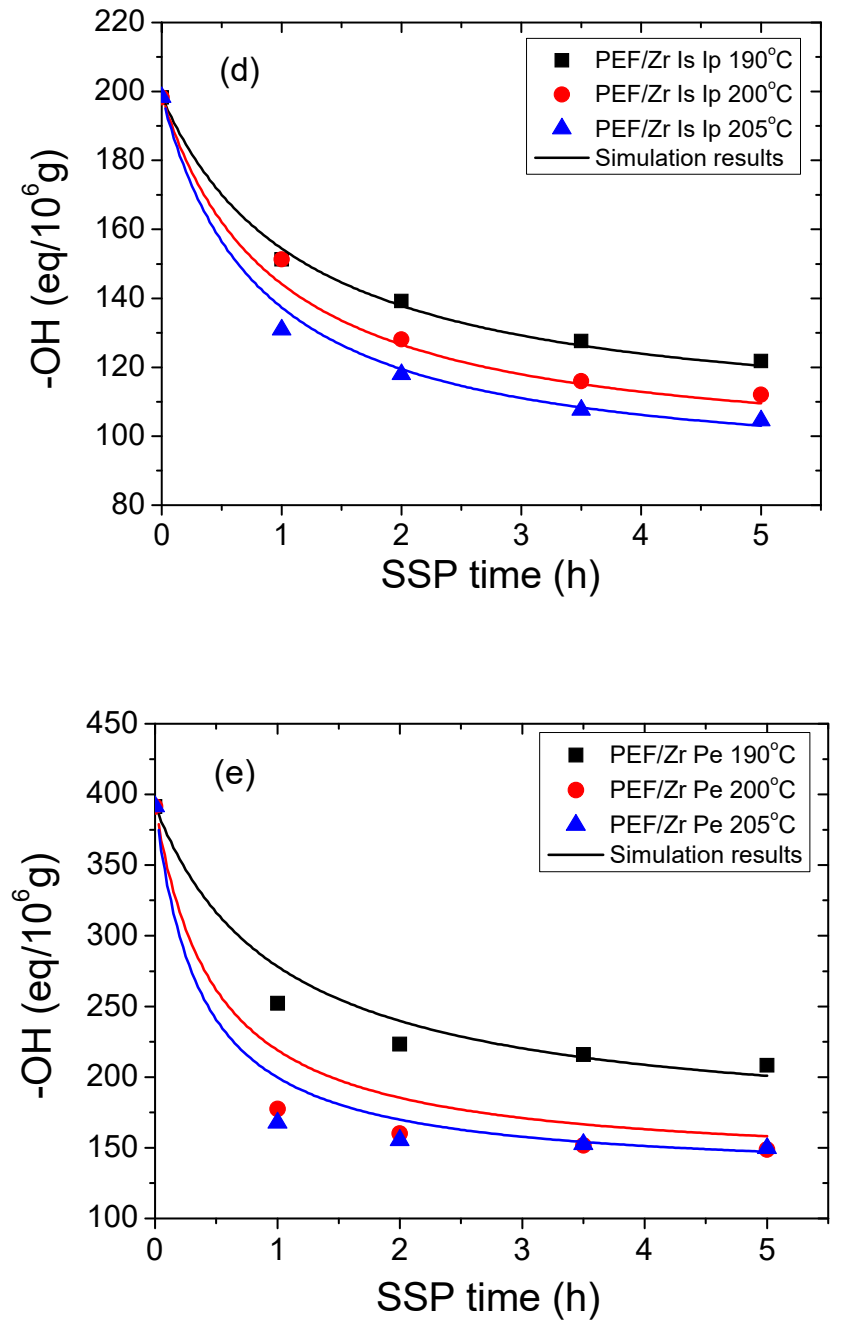

Figure 4. Variation of hydroxyl end-groups with time during PEF/Sb Ac (a), PEF/Ge Ox (b), PEF/Sb $\mathrm{Ox}(\mathbf{c}), \mathrm{PEF} / \mathrm{Zr}$ Is Ip (d), and PEF/Zr Pe (e) SSP at different temperatures. Continuous lines represent the theoretical kinetic model simulation result.

Table 2. Kinetic rate constants of the transesterification and esterification reaction and concentration of temporarily inactivated $\mathrm{OH}$ and $\mathrm{COOH}$ end-groups at different polycondensation temperatures of $\mathrm{PEF} / \mathrm{Sb} \mathrm{Ac}, \mathrm{PEF} / \mathrm{Ge} \mathrm{Ox}, \mathrm{PEF} / \mathrm{Sb} \mathrm{Ox}, \mathrm{PEF} / \mathrm{Zr}$ Is Ip, and PEF/Zr Pe.

\begin{tabular}{cccccc}
\hline Sample & Temp. $\left({ }^{\circ} \mathbf{C}\right)$ & $\left.\mathbf{k}_{\mathbf{1}} \mathbf{( k g} / \mathbf{m e q}\right) \mathbf{h}^{-\mathbf{1}}$ & $\mathbf{k}_{\mathbf{2}} \mathbf{( \mathbf { k g } / \mathbf { m e q } ) \mathbf { h } ^ { - \mathbf { 1 } }}$ & {$[\mathbf{O H}]_{\mathbf{i}} \mathbf{( \mathbf { m e q } / \mathbf { k g } )}$} & {$[\mathbf{C O O H}]_{\mathbf{i}}(\mathbf{m e q} / \mathbf{k g})$} \\
\hline PEF/Sb Ac & 190 & $24 \times 10^{-4}$ & $50 \times 10^{-4}$ & 162 & 13 \\
& 200 & $46 \times 10^{-4}$ & $76 \times 10^{-4}$ & 150 & 7.5 \\
& 205 & $59 \times 10^{-4}$ & $92 \times 10^{-4}$ & 138 & 6.0 \\
\hline PEF/Ge Ox & 190 & $5.5 \times 10^{-4}$ & $22 \times 10^{-4}$ & 162 & 13 \\
& 200 & $10 \times 10^{-4}$ & $31 \times 10^{-4}$ & 150 & 10 \\
& 205 & $21 \times 10^{-4}$ & $46 \times 10^{-4}$ & 138 & 6.0 \\
\hline PEF/Sb Ox & 190 & $10 \times 10^{-4}$ & $23 \times 10^{-4}$ & 162 & 9.5 \\
& 200 & $20 \times 10^{-4}$ & $27 \times 10^{-4}$ & 150 & 6.0 \\
PEF/Zr Is Ip & 205 & $32 \times 10^{-4}$ & $30 \times 10^{-4}$ & 138 & 13 \\
& 190 & $37 \times 10^{-4}$ & $43 \times 10^{-4}$ & 105 & 6 \\
PEF/Zr Pe & 200 & $42 \times 10^{-4}$ & $52 \times 10^{-4}$ & 96 & 13 \\
& 205 & $46 \times 10^{-4}$ & $57 \times 10^{-4}$ & 91 & 10 \\
& 190 & $21 \times 10^{-4}$ & $20 \times 10^{-4}$ & 162 & 4.5 \\
\hline
\end{tabular}



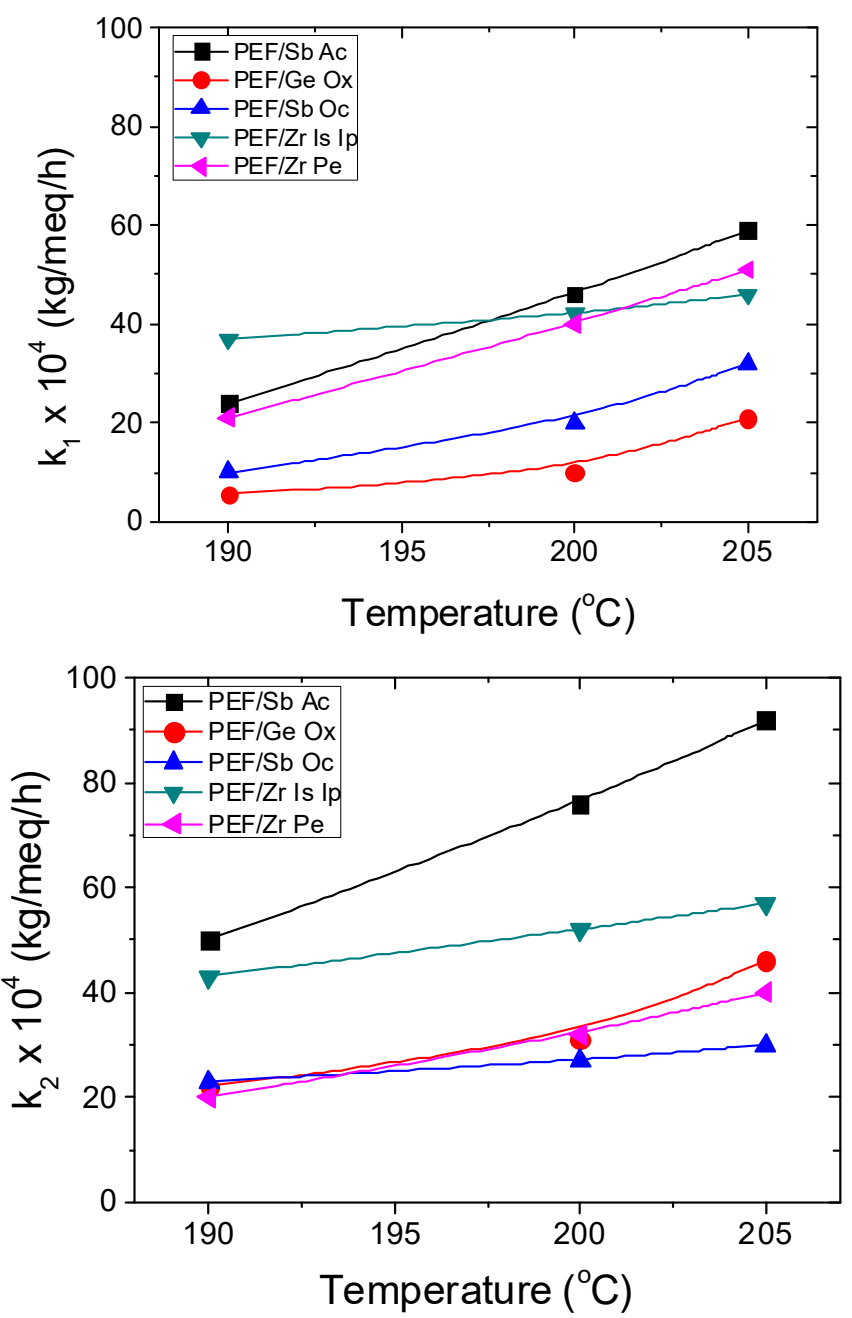

Figure 5. Variation of the estimated kinetic rate constants for polycondensation $\left(k_{1}\right)$ and esterification $\left(k_{2}\right)$ with temperature for all catalytic systems investigated.

From the data illustrated in Table 2 it seems that the values of the transesterification rate constant, $\mathrm{k}_{1}$, is lower than that of the esterification rate constant, $\mathrm{k}_{2}$, for all polyesters except PEF/Zr Pe, where similar values were estimated. The lower polycondensation rate constants, such as $k_{1}$, were estimated for PEF/Ge Ox followed by PEF/Sb Ox. These catalysts also together with PEF/Zr Pe exhibited the lower esterification rate constants, $k_{2}$. This is an indication that the effectiveness of these catalysts was lower compared to the other two investigated, i.e., PEF/Zr Is Ip and PEF/Sb Ac. It should be pointed here that the latter catalyst system (i.e., $\mathrm{PEF} / \mathrm{Sb} \mathrm{Ac}$ ) exhibited always the higher $\mathrm{k}_{2}$ values followed by PEF/Zr Is Ip, which, even at 200 and $205^{\circ} \mathrm{C}$, had the highest $\mathrm{k}_{1}$ values. This can be explained since the relative increase in the average molecular weight achieved by the $\mathrm{Sb}$ Ac catalyst, for example after $5 \mathrm{~h} \mathrm{SSP}$ at $205^{\circ} \mathrm{C}$, was almost $200 \%$ compared to the corresponding of $\mathrm{Zr}$ Is Ip, which was almost $100 \%$. Hence, it can be postulated that the $\mathrm{Sb}$ Ac catalyst provides the higher kinetic rate constants compared to all other catalysts, followed by Zr Is Ip.

In addition, from Table 2 it was estimated that the best fit values for the hydroxyl inactive groups, $[\mathrm{OH}]_{\mathrm{i}}$, meaning those which are inaccessible to react, are always lower in PEF/Zr Is Ip compared to the other polyesters, while they always reduce with increasing temperature. An increase in temperature improves the mobility of the polymer chains and thus reduces the number of inactive end species. The lower values in PEF/Zr Is Ip are a direct consequence of the always lower -OH end-group concentration measured at all reaction times and temperatures compared to other polyesters 
(see Figure 4). Concerning the inactive $[\mathrm{COOH}]_{\mathrm{i}}$, the values are always low enough and similar for all catalytic systems investigated.

Finally, both kinetic rate constants were correlated with temperature using an Arrhenius-type expression. As it is expected, the values of all rate constants increase with SSP temperature in accordance with the mobility and activity of the chain ends. When plotting $\ln (k) \mathrm{vs} 1 / T$, good straight lines were obtained with a correlation coefficient greater than 0.90 (Table 3). From the slope of these straight lines the activation energies for the transesterification, $E_{1}$, and esterification, $E_{2}$, reactions were determined and illustrated in Table 3. Moreover, form the intercept of these straight lines the pre-exponential factors can be calculated and are also included in the same Table. It should be noted that the estimation of the activation energies using only three experimental data points (at the three investigated temperatures) results in a somehow great uncertainty in the values denoted by their high standard deviation. Thus, a safe conclusion concerning the activation energies cannot be set. However, there a definite indication that the PEF/Zr Is Ip system has a much lower $E_{1}$ compared to all other systems and, an $E_{2}$, which, within experimental error, seems to be also the lower one. In contrast the highest activation energy was measured when Ge Ox was used as a catalyst. This model results verify the fact that certainly $\mathrm{Zr}$ Is Ip exhibits the best catalytic characteristics compared to the other catalysts employed lowering the activation energy of both reactions involved during SSP.

Table 3. Activation energies, pre-exponential factors, and correlation coefficients of the transesterification and esterification reaction of all PEF polyesters.

\begin{tabular}{ccccccc}
\hline Sample & $\left.\boldsymbol{E}_{\mathbf{1}} \mathbf{( k J / m o l}\right)$ & $\boldsymbol{l n}\left(\boldsymbol{k}_{\mathbf{0 1}} \times \mathbf{1 0}^{\mathbf{4}}\right)$ & $\boldsymbol{R}^{\mathbf{2}}$ & $\left.\boldsymbol{E}_{\mathbf{2}} \mathbf{( k J / m o l}\right)$ & $\ln \left(\boldsymbol{k}_{\mathbf{0 2}} \times \mathbf{1 0}^{\mathbf{4}}\right)$ & $\boldsymbol{R}^{\mathbf{2}}$ \\
\hline $\mathrm{PEF} / \mathrm{Sb} \mathrm{Ac}$ & $111.6 \pm 6.1$ & $32.18 \pm 1.55$ & 0.994 & $75.1 \pm 1.1$ & $23.41 \pm 0.27$ & 0.999 \\
$\mathrm{PEF} / \mathrm{Ge} \mathrm{Ox}$ & $158.7 \pm 19.6$ & 42.887 .28 & 0.937 & $86.3 \pm 15.1$ & 25.485 .35 & 0.898 \\
$\mathrm{PEF} / \mathrm{Sb}$ Ox & $140.3 \pm 12.3$ & $38.72 \pm 3.14$ & 0.985 & $32.3 \pm 2.5$ & $11.47 \pm 0.65$ & 0.987 \\
$\mathrm{PEF} / \mathrm{Zr} \mathrm{Ip} \mathrm{Is}$ & $26.2 \pm 2.7$ & $10.40 \pm 0.70$ & 0.979 & $34.6 \pm 0.1$ & $12.75 \pm 0.01$ & 0.999 \\
$\mathrm{PEF} / \mathrm{Zr} \mathrm{Pe}$ & $110.2 \pm 6.3$ & $31.67 \pm 1.62$ & 0.993 & $85.2 \pm 0.4$ & $25.11 \pm 0.11$ & 0.999 \\
\hline
\end{tabular}

\subsection{Thermal Analysis of PEF Polyester Samples Prepared by Solid-State Polymerization}

The DSC results showed that the thermal properties of PEF were found to be obviously enhanced after the SSP procedure. Figure 6 and Figures S1-S4 in Supporting Information highlighted the melting behavior of PEF polyester samples at different reaction times and temperatures. As can be seen, regardless the catalyst type used, the endothermic melting peaks were shifted to higher values (increased $T_{\mathrm{m}}$ ) with increasing of either SSP time or SSP temperature, with an accompanying increase in the degree of crystallinity of resulting polymer. As expected, the increased molecular weight of the polyester sample during SSP process triggers the increase of the sharpness of the melting peaks as well as the increase in the melting points. Interestingly, DSC heating scans of PEF samples revealed double melting endotherms for PEF/Sb Ac, PEF/Ge Ox, and PEF/Zr Pe catalytic systems at the lowest SSP temperature $\left(190^{\circ} \mathrm{C}\right)$ performed at $t_{\mathrm{ssp}} 1 \mathrm{~h}$. This behavior is mainly time dependent and it has been completely vanished for PEF/Sb Ac and PEF/Ge Ox at $2 \mathrm{~h}$ of SSP, while for PEF/Zr Pe, the double peaks have been merged to one after $3 \mathrm{~h}$. This outcome could be ascribed to crystals with different sizes and perfections induced by the thermal treatments of polymer as well as the annealing process $[69,74,80-82]$. This finding was recently reported in our previous work [70] for SSP process of PEF using three different catalysts, that is, titanium (IV) isopropoxide, dibutyltin (IV) oxide, and tetrabutyltitanate. Moreover, similar multiple melting peaks have been commonly detected during SSP in some alipharomatic polyesters like PET [85-87]. For PEF/Zr Is Ip, only one melting peak was recorded, which means that neither increasing SSP temperature nor time could change the behavior of the obtained polymer. Furthermore, PEF/Sb Ox exhibited double melting peaks after $2 \mathrm{~h}$ SSP process and they did not disappear even after $5 \mathrm{~h}$. This is could be associated with the formation of two different types of persistent crystal formation. It is worth noting that the enthalpy of fusion 
$\left(\mathrm{DH}_{\mathrm{m}}\right)$ is also time- and temperature-dependent, that is, it increases progressively either increasing the SSP time or the SSP temperature.

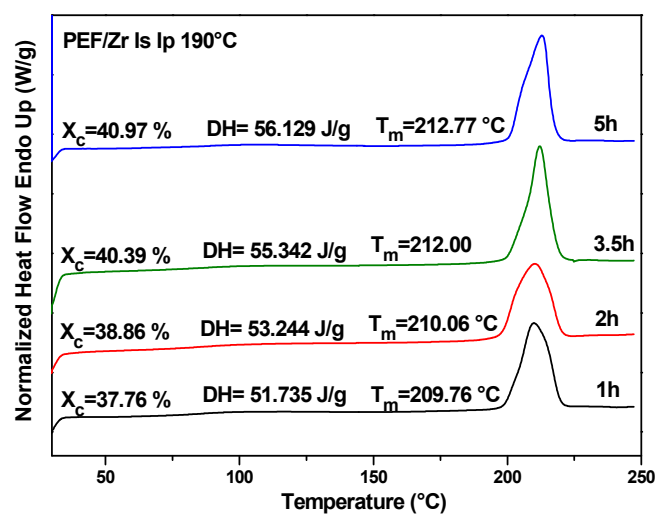

(a)

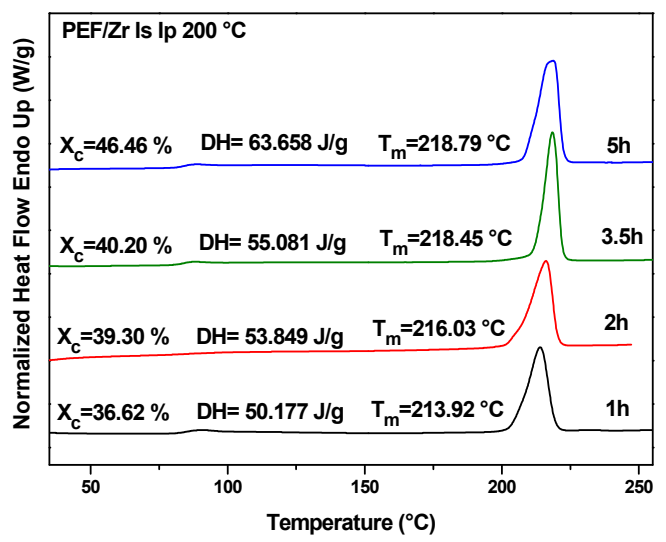

(b)

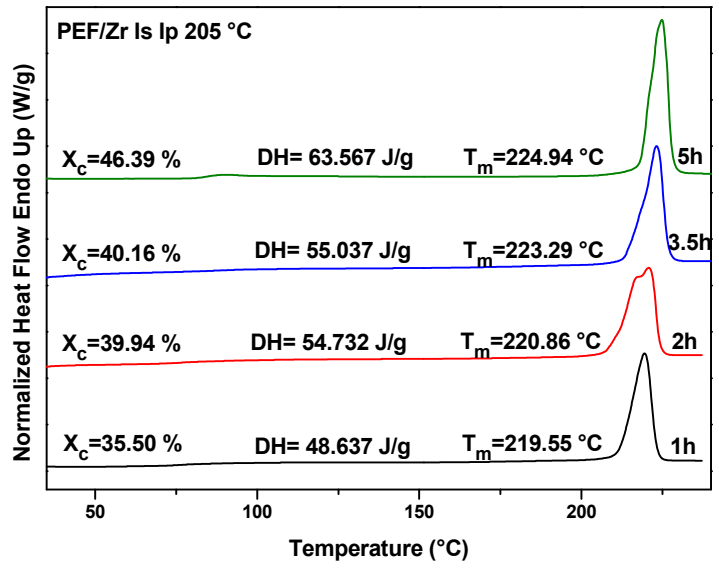

(c)

Figure 6. Differential scanning calorimetry (DSC) thermograms of different PEF/Zr Is Ip samples prepared after SSP at different temperatures and times: (a) $190{ }^{\circ} \mathrm{C}$, (b) $200{ }^{\circ} \mathrm{C}$, and (c) $205^{\circ} \mathrm{C}$.

As the degree of crystallinity $\left(X_{c}\right)$ in semicrystalline polymers plays an important role in determining the final properties of resulting materials, that is, it has a direct bearing on the polymers optical, mechanical, chemical, and thermal properties, $X_{\mathrm{c}}$ for all prepared SSP PEF samples (presented in Table 4) was calculated from the measured melting enthalpy $\left(\mathrm{DH}_{\mathrm{m}}\right)$ values, using the heat of fusion value for the pure crystalline PEF that was reported in a previous study to be about $137 \mathrm{~J} \cdot \mathrm{g}^{-1}$ [55]. As depicted in Figure 7, whatever SSP time and temperature were used, the PEF/Zr Is Ip system exhibits much lower $X_{\mathrm{c}}$ values compared to those of other systems. PEF/Sb Ac, PEF/Ge Ox, PEF/Sb Ox, and PEF/Zr Pe have almost similar $X_{\mathrm{C}}$ values at $205^{\circ} \mathrm{C}$, with a difference average up to $4 \%$, while $\mathrm{PEF} / \mathrm{Zr}$ Is Ip showed at the same temperature a much lower values, with respect to the latter four (difference average of $17 \%$ ). It has been clearly illustrated in Table 4 that $X_{\mathrm{c}}$ follows the same trend of SSP temperature, that is, achieving the highest value at temperatures close to the melting point of PEF samples. This is associated with the higher macromolecular chain mobility and thereby higher folding ability to create crystalline lamellae. Since SSP occurs in the amorphous regions of the semi crystalline polyester, where end-groups are excluded from crystalline regions, it can thus be concluded that the rapidly increasing IV/molecular weight rate of PEF/Zr Is Ip, compared with the others four polyester 
samples, is due to its lowest degree of crystallinity, as indicated in Figure 7. The latter induces an increase in the chain mobility, which becomes less restricted, hence leading to a more facile diffusion rate of reaction by-products (ethylene glycol and water) by imposing a lower degree of resistance to mass transfer. Thus, this implies that molecular weight increase became faster. The $M_{n} / I V$ values obtained in the current study are in good accordance with this explanation.

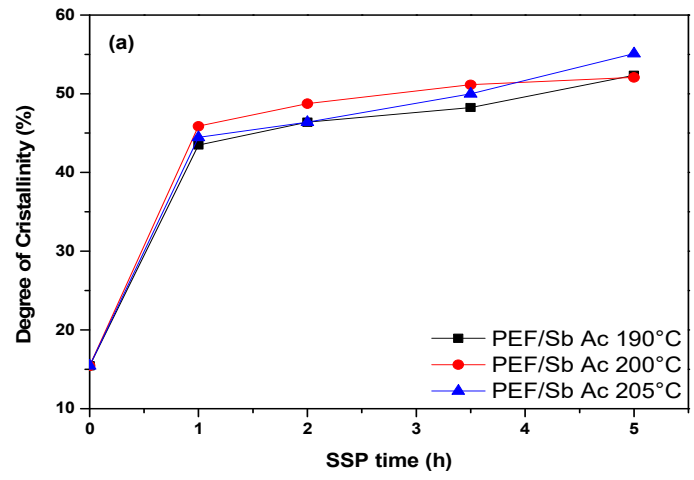

(a)

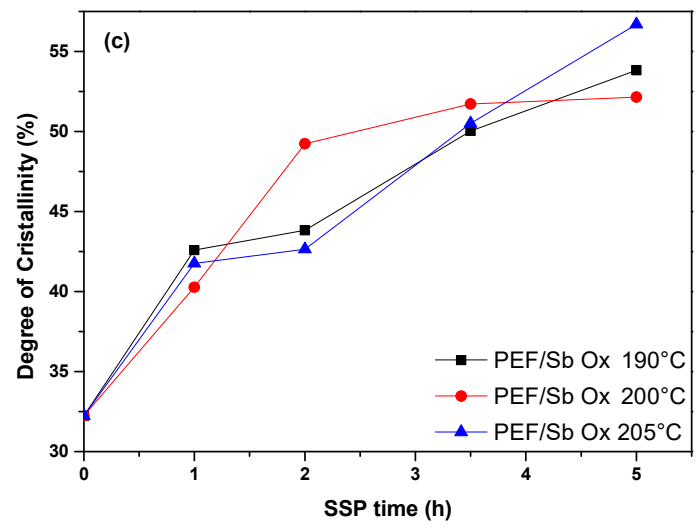

(c)

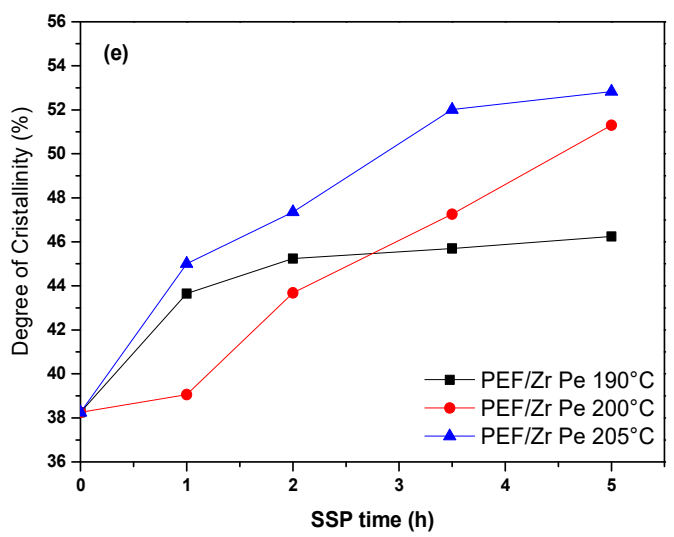

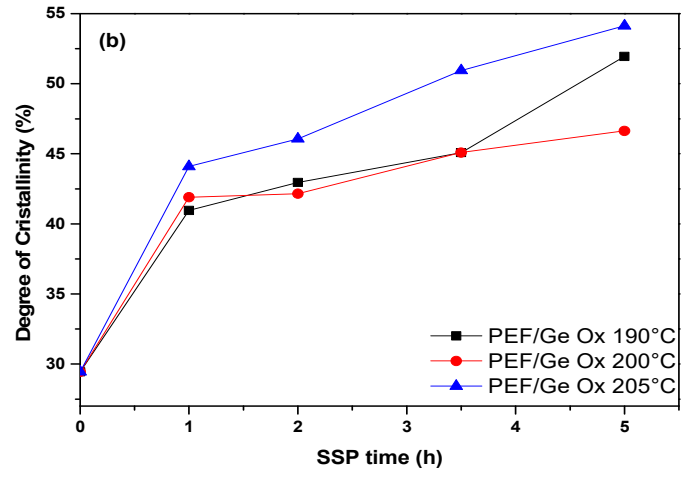

(b)

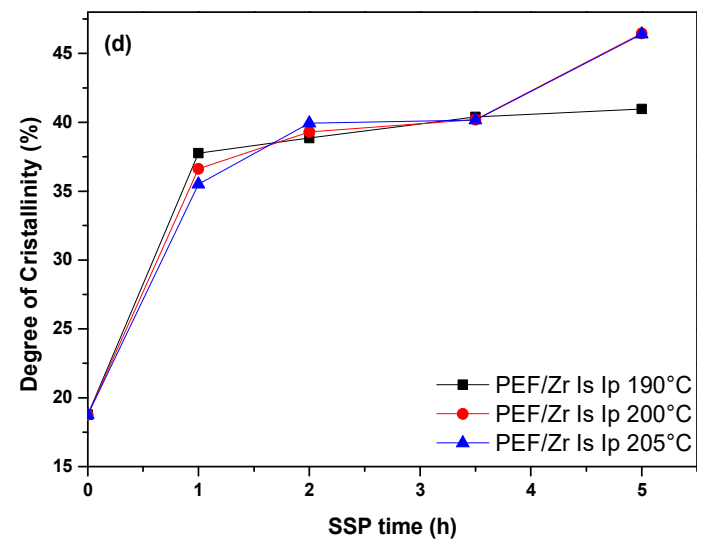

(d)

(e)

Figure 7. Effect of SSP time and temperature on the evolution of the degree of crystallinity of PEF samples: (a) PEF/Sb Ac, (b) PEF/Ge Ox, (c) PEF/Sb Ox, (d) PEF/Zr Is Ip, and (e) PEF/Zr Pe. 
Table 4. Degree of crystallinity values (\%) of the SSP PEF samples using different catalysts.

\begin{tabular}{ccccccc}
\hline SSP Temperature $\left({ }^{\circ} \mathbf{C}\right)$ & SSP time $(\mathbf{h})$ & PEF/Sb Ac & PEF/Ge Ox & PEF/Sb Ox & PEF/Zr Is Ip & PEF/Zr Pe \\
\hline & 0 & 15.43 & 29.44 & 32.23 & 18.76 & 38.25 \\
\hline \multirow{3}{*}{190} & 1 & 43.49 & 40.96 & 42.59 & 37.76 & 43.65 \\
& 2 & 46.38 & 42.96 & 43.83 & 38.86 & 45.24 \\
& 3.5 & 48.25 & 45.08 & 50.03 & 40.39 & 45.70 \\
& 5 & 52.35 & 51.95 & 53.83 & 40.97 & 46.24 \\
\hline \multirow{2}{*}{200} & 1 & 45.88 & 41.90 & 40.27 & 36.62 & 39.06 \\
& 2 & 48.74 & 42.15 & 49.24 & 39.30 & 43.68 \\
& 3.5 & 51.15 & 45.09 & 51.72 & 40.20 & 47.26 \\
& 5 & 52.07 & 46.64 & 52.15 & 46.46 & 51.30 \\
\hline & 1 & 44.46 & 44.10 & 41.76 & 35.50 & 45.01 \\
& 2 & 46.39 & 46.07 & 42.65 & 39.94 & 47.36 \\
& 3.5 & 50.00 & 50.94 & 50.50 & 40.16 & 52.01 \\
\hline
\end{tabular}

\section{Conclusions}

Solid-state polymerization of the ecofriendly polyester PEF was investigated with a variety of catalysts at several temperatures. The effect of catalyst type, which is an important parameter influencing the SSP kinetics on molecular weight increase, of the resultant polyesters was discussed in detail, both experimentally and using a simple kinetic model. As SSP temperature and time increased, the intrinsic viscosity and the average molecular weight of PEF also increased. This is owing to the elimination of formed by-products during both the transesterification and esterification reactions that occurring during SSP, are diffusion-controlled. A simple kinetic model was also developed and used to get a deeper insight into the PEF polyester's intrinsic viscosity as well as hydroxyl and carboxyl end-groups content by prediction their time evolution during SSP. From both the theoretical simulation results and the experimental measurements, it is proven that $\mathrm{Zr}$ Is Ip catalyst resulted in lower activation energies of both responsible reactions on the molecular weight increase during SSP. This finding explains the obtaining of higher molecular weight PEF samples with respect to those prepared using other catalysts. In contrast, the presence of the Ge Ox catalyst resulted in the highest activation energies, thus, leading to lower molecular weight PEF, as confirmed by IV measurement obtained herein. As an overall conclusion for the five catalysts used in the current work, Zr Is Ip displayed the best catalytic characteristics during SSP procedure.

Supplementary Materials: The following are available online at http:/ /www.mdpi.com/2073-4360/11/3/438/s1, Figure S1: DSC thermograms of PEF/Sb Ac samples prepared after SSP at different temperatures and times, Figure S2: DSC thermograms of PEF/Ge Ox samples prepared after SSP at different temperatures and times. Figure S3: DSC thermograms of PEF/Zr Pe samples prepared after SSP at different temperatures and times. Figure S4: DSC thermograms of PEF/Sb Ox samples prepared after SSP at different temperatures and times.

Author Contributions: Supervision, D.N.B., G.Z.P., and M.M.; Conceptualization, D.N.B. and G.Z.P.; Data Curation, Y.C. and N.K.; Investigation, Y.C. and N.K.; Kinetic Model Simulation Performance, D.S.A. Writing-Original Draft Preparation, N.K. and Y.C.; Writing-Review and Editing, D.N.B.

Conflicts of Interest: The authors declare no conflicts of interest.

\section{References}

1. Gandini, A. Polymers from Renewable Resources: A Challenge for the Future of Macromolecular Materials. Macromolecules 2008, 41, 9491-9504. [CrossRef]

2. Walther, G. High-Performance Polymers from Nature: Catalytic Routes and Processes for Industry. ChemSusChem. 2014, 7, 2081-2088. [CrossRef] [PubMed]

3. Meier, M.A.R.; Metzger, J.O.; Schubert, U.S. Plant oil renewable resources as green alternatives in polymer science. Chem. Soc. Rev. 2007, 36, 1788-1802. [CrossRef] [PubMed] 
4. Gandini, A.; Lacerda, T.M.; Carvalho, A.J.F.; Trovatti, E. Progress of Polymers from Renewable Resources: Furans, Vegetable Oils, and Polysaccharides. Chem. Rev. 2016, 116, 1637-1669. [CrossRef] [PubMed]

5. Llevot, A.; Dannecker, P.K.; Von Czapiewski, M.; Over, L.C.; Söyler, Z.; Meier, M.A.R. Renewability is not Enough: Recent Advances in the Sustainable Synthesis of Biomass-Derived Monomers and Polymers. Chem. Eur. J. 2016, 22, 11510-11521. [CrossRef] [PubMed]

6. Iwata, T. Cheminform abstract: Biodegradable and bio-based polymers: Future prospects of eco-friendly plastics. Angew. Chem. Int. Ed. 2015, 54, 3210-3215. [CrossRef] [PubMed]

7. Bond, J.Q.; Alonso, D.M.; Wang, D.; West, R.M.; Dumesic, J.A. Integrated catalytic conversion of $\gamma$-valerolactone to liquid alkenes for transportation fuels. Science 2010, 327, 1110-1114. [CrossRef] [PubMed]

8. BioPreferred-Directives for the Mandatory Purchasing of Biobased Products. Available online: http://www. biopreferred.gov/BioPreferred/faces/pages/AboutBioPreferred.xhtml (accessed on 19 January 2019).

9. Industrial Sustainability-European Commission. Available online: http://ec.europa.eu/growth/industry/ sustainability/index_en.htm (accessed on 19 January 2019).

10. Brodin, M.; Vallejos, M.; Opedal, M.T.; Area, M.C.; Chinga-Carrasco, G. Lignocellulosics as sustainable resources for production of bioplastics-A review. J Clean. Prod. 2017, 162, 646-664. [CrossRef]

11. Kamm, B.; Kamm, M. Principles of biorefineries. Appl. Microbiol. Biotechnol. 2004, 64, 137-145. [CrossRef] [PubMed]

12. Van Putten, R.J.; Van Der Waal, J.C.; De Jong, E.; Rasrendra, C.B.; Heeres, H.J.; De Vries, J.G. Hydroxymethylfurfural, a versatile platform chemical made from renewable resources. Chem. Rev. 2013, 113, 1499-1597. [CrossRef] [PubMed]

13. Nai, L.; Zheng, Y.; Wei, L.; Teng, H.; Zhou, J. Metal nanoparticles supported on $\mathrm{WO}_{3}$ nanosheets for highly selective hydrogenolysis of cellulose to ethylene glycol. Green Chem. 2017, 19, 682-691. [CrossRef]

14. Rizescu, C.; Podolean, I.; Albero, J.; Parvulescu, V.I.; Coman, S.M.; Bucur, C.; Puchec, M.; Garcia, H. N-Doped graphene as a metal-free catalyst for glucose oxidation to succinic acid. Green Chem. 2017, 19, 1999-2005. [CrossRef]

15. Jong, E.; Dam, M.A.; Sipos, L.; Gruter, G.J. Furandicarboxylic acid (FDCA), a versatile building block for a very interesting class of polyesters. ACS Symp. Ser. 2012, 1105, 1-13. [CrossRef]

16. Bozell, J.J.; Petersen, G.R. Technology development for the production of bio-based products from 28 biorefinery carbohydrates-the US department of energy's “Top 10" revisited. Green Chem. 2010, 12, 539-554. [CrossRef]

17. Vannini, M.; Marchese, P.; Celli, A.; Lorenzetti, C. Fully biobased poly(propylene 2,5-furandicarboxylate) for packaging applications: Excellent barrier properties as a function of crystallinity. Green Chem. 2015, 17, 4162-4166. [CrossRef]

18. Tsanaktsis, V.; Terzopoulou, Z.; Nerantzaki, M.; Papageorgiou, G.Z.; Bikiaris, D.N. New poly(pentylene furanoate) and poly(heptylene furanoate) sustainable polyesters from diols with odd methylene groups. Mater. Lett. 2016, 178, 64-67. [CrossRef]

19. Genovese, L.; Lotti, N.; Siracusa, V.; Munari, A. Poly(Neopentyl glycol furanoate): A member of the furan-based polyester family with smart barrier performances for sustainable food packaging applications. Materials 2017, 10, 1028. [CrossRef] [PubMed]

20. Papageorgiou, D.G.; Guigo, N.; Tsanaktsis, V.; Exarhopoulos, S.; Bikiaris, D.N.; Sbirrazzuoli, N.; Papageorgiou, G.Z. Fast crystallization and melting behavior of a long-spaced aliphatic furandicarboxylate bio-based polyester, the poly(dodecylene 2,5-furanoate). Ind. Eng. Chem. Res. 2016, 55, 5315-5326. [CrossRef]

21. Soccio, M.; Martínez-Tong, D.E.; Alegría, A.; Munari, A.; Lotti, N. Molecular dynamics of fully biobased poly(butylene 2,5-furanoate) as revealed by broadband dielectric spectroscopy. Polymer 2017, 128, 24-30. [CrossRef]

22. Soares, M.J.; Dannecker, P.-K.; Vilela, C.; Bastos, J.; Meier, M.A.R.; Sousa, A.F. Poly(1,20-eicosanediyl 2,5-furandicarboxylate), a biodegradable polyester from renewable resources. Eur. Polym. J. 2017, 90, 301-311. [CrossRef]

23. Tsanaktsis, V.; Terzopoulou, Z.; Exarhopoulos, S.; Bikiaris, D.N.; Achilias, D.S.; Papageorgiou, D.G.; Papageorgiou, G.Z. Sustainable, eco-friendly polyesters synthesized from renewable resources: Preparation and thermal characteristics of poly(dimethyl-propylene furanoate). Polym. Chem. 2015, 6, 8284-8296. [CrossRef]

24. Carlos Morales-Huerta, J.; Martínez De Ilarduya, A.; Muñoz-Guerra, S. Poly(alkylene 2,5- furandicarboxylate)s (PEF and PBF) by ring opening polymerization. Polymer 2016, 87, 148-158. [CrossRef] 
25. Tsanaktsis, V.; Papageorgiou, G.Z.; Bikiaris, D.N. A Facile Method to Synthesize High-Molecular-Weight Biobased Polyesters from 2,5-Furandicarboxylic Acid and Long-Chain Diols. J. Polym. Sci. Part A Polym. Chem. 2015, 53, 2617-2632. [CrossRef]

26. Genovese, L.; Soccio, M.; Lotti, N.; Munari, A.; Szymczyk, A.; Paszkiewicz, S.; Linares, A.; Nogales, A.; Ezquerra, T.A. Effect of chemical structure on the subglass relaxation dynamics of biobased polyesters as revealed by dielectric spectroscopy: 2,5-furandicarboxylic acid vs. trans-,4-cyclohexanedicarboxylic acid. Phys. Chem. Chem. Phys. 2018, 20, 15696-15706. [CrossRef] [PubMed]

27. Matos, M.; Sousa, A.F.; Silvestre, A.J.D. Improving the Thermal Properties of Poly(2,5-furandicarboxylate)s Using Cyclohexylene Moieties: A Comparative Study. Macromol. Chem. Phys. 2017, 218, 1600492. [CrossRef]

28. Wang, J.; Liu, X.; Jia, Z.; Sun, L.; Zhang, Y.; Zhu, J. Modification of poly(ethylene 2,5-furandicarboxylate) (PEF) with 1,4-cyclohexanedimethanol: Influence of stereochemistry of 1,4-cyclohexylene units. Polymer 2018, 137, 173-185. [CrossRef]

29. Sousa, A.F.; Vilela, C.; Fonseca, A.C.; Matos, M.; Freire, C.S.R.; Gruter, G.-J.M.; Coelho, J.F.J.; Silvestre, A.J.D. Biobased polyesters and other polymers from 2,5-furandicarboxylic acid: A tribute to furan excellence. Polym. Chem. 2015, 6, 5961-5983. [CrossRef]

30. Papageorgiou, G.Z.; Papageorgiou, D.G.; Terzopoulou, Z.; Bikiaris, D.N. Production of bio-based 2,5-furan dicarboxylate polyesters: Recent progress and critical aspects in their synthesis and thermal properties. Eur. Polym. J. 2016, 83, 202-229. [CrossRef]

31. Thiyagarajan, S.; Vogelzang, W.J.I.; Knoop, R.; Frissen, A.E.; Van Haveren, J.; Van Es, D.S. Biobased furandicarboxylic acids (FDCAs): Effects of isomeric substitution on polyester synthesis and properties. Green Chem. 2014, 16, 1957-1966. [CrossRef]

32. Weinberger, S.; Canadell, J.; Quartinello, F.; Yeniad, B.; Arias, A.; Pellis, A.; Guebitz, G.M. Enzymatic Degradation of Poly(ethylene 2,5-furanoate) Powders and Amorphous Films. Catalysts 2017, 7, 318. [CrossRef]

33. Tsanaktsis, V.; Papageorgiou, D.G.; Exarhopoulos, S.; Bikiaris, D.N.; Papageorgiou, G.Z. Crystallization and Polymorphism of Poly(Ethylene Furanoate). Cryst. Growth Des. 2015, 15, 5505-5512. [CrossRef]

34. Eerhart, A.J.J.E.; Faaij, A.P.C.; Patel, M.K. Replacing fossil based PET with biobased PEF; process analysis, energy and GHG balance. Energy Environ. Sci. 2012, 5, 6407-6422. [CrossRef]

35. Burgess, S.K.; Leisen, J.E.; Kraftschik, B.E.; Mubarak, C.R.; Kriegel, R.M.; Koros, W.J. Chain Mobility, Thermal, and Mechanical Properties of Poly(Ethylene Furanoate) Compared to Poly(Ethylene Terephthalate). Macromolecule 2014, 47, 1383-1391. [CrossRef]

36. Burgess, S.K.; Kriegel, R.M.; Koros, W.J. Carbon dioxide sorption and transport in amorphous poly(ethylene furanoate). Macromolecules 2015, 48, 2184-2193. [CrossRef]

37. PEF: Game-Changing Plastic. Available online: https://www.avantium.com/yxy/products-applications / (accessed on 28 January 2019).

38. Gruter, G.-J.M.; Sipos, L.; Dam, M.A. Accelerating Research into Bio-Based FDCA-Polyesters by Using Small Scale Parallel Film Reactors. Comb. Chem. High Throughput Screen. 2012, 15, 180-188. [CrossRef] [PubMed]

39. Wang, J.G.; Liu, X.Q.; Zhang, Y.J.; Liu, F.; Zhu, J. Modification of poly(ethylene 2,5-furandicarboxylate) with 1,4-cyclohexanedimethylene: Influence of composition on mechanical and barrier properties. Polymer 2016, 103, 1-8. [CrossRef]

40. Rosenboom, J.-G.; Hohl, D.K.; Fleckenstein, P.; Storti, G.; Morbidelli, M. Bottle-grade polyethylene furanoate from ring-opening polymerisation of cyclic oligomers. Nat. Commun. 2018, 9, 2701. [CrossRef] [PubMed]

41. Steinborn-Rogulska, I.; Rokicki, G. Solid-state polycondensation (SSP) as a method to obtain high molecular weight polymers. Part II. Synthesis of polylactide and polyglycolide via SSP. Polimery 2013, 58, 85-92. [CrossRef]

42. Achilias, D.S.; Bikiaris, D.N.; Karavelidis, V.; Karayannidis, G.P. Effect of silica nanoparticles on solid state polymerization of poly(ethylene terephthalate). Eur. Polym. J. 2008, 44, 3096-3107. [CrossRef]

43. Vouyiouka, S.N.; Karakatsani, E.K.; Papaspyrides, C.D. Solid state polymerization. Prog. Polym. Sci. 2005, 30, $10-37$. [CrossRef]

44. Karayannidis, G.P.; Kokkalas, D.E.; Bikiaris, D.N. Solid-state polycondensation of poly(ethylene terephthalate) recycled from postconsumer soft-drink bottles. II. J. Appl. Polym. Sci. 1995, 56, 405-410. [CrossRef] 
45. Zhang, J.; Shen, X.-J.; Zhang, J.; Feng, L.-F.; Wang, J.-J. Experimental and modeling study of the solid state polymerization of poly(ethylene terephthalate) over a wide range of temperatures and particle sizes. J. Appl. Polym. Sci. 2013, 127, 3814-3822. [CrossRef]

46. Bikiaris, D.; Karavelidis, V.; Karayannidis, G. A New Approach to Prepare Poly(ethylene terephthalate)/Silica Nanocomposites with Increased Molecular Weight and Fully Adjustable Branching or Crosslinking by SSP. Macromol. Rapid Commun. 2006, 27, 1199-1205. [CrossRef]

47. Li, L.-J.; Duan, R.-T.; Zhang, J.-B.; Wang, X.-L.; Chen, L.; Wang, Y.-Z. Phosphorus-Containing Poly(ethylene terephthalate): Solid-State Polymerization and Its Sequential Distribution. Ind. Eng. Chem. Res. 2013, 52, 5326-5333. [CrossRef]

48. Papaspyrides, C.D.; Vouyiouka, S.N. Solid State Polymerization, 1st ed.; John Wiley \& Sons, Inc.: Hoboken, NJ, USA, 2009; pp. 1-294. ISBN 9780470084182.

49. Gantillon, B.; Spitz, R.; McKenna, T.F. The Solid State Postcondensation of PET, 1: A Review of the Physical and Chemical Processes Taking Place in the Solid State. Macromol. Mater. Eng. 2004, 289, 88-105. [CrossRef]

50. Burgess, S.K.; Karvan, O.; Johnson, J.R.; Kriegel, R.M.; Koros, W.J. Oxygen sorption and transport in amorphous poly (ethylene furanoate). Polymer 2014, 55, 4748-4756. [CrossRef]

51. Burgess, S.K.; Wenz, G.B.; Kriegel, R.M.; Koros, W.J. Penetrant Transport in Semicrystalline Poly(Ethylene Furanoate). Polymer 2016, 98, 305-310. [CrossRef]

52. Koros, W.J.; Burgess, S.K.; Chen, Z. Polymer Transport Properties. In Encyclopedia of Polymer Science and Technology; John Wiley \& Sons, Inc.: Hoboken, NJ, USA, 2002.

53. Gopalakrishnan, P.; Narayan-Sarathy, S.; Ghosh, T.; Mahajan, K.; Belgacem, M.N. Synthesis and Characterization of Bio-Based Furanic Polyesters. J. Polym. Res. 2014, 21, 340. [CrossRef]

54. Gomes, M.; Gandini, A.; Silvestre, A.J.D.; Reis, B. Synthesis and Characterization of Poly(2,5-Furan Dicarboxylate)s Based on a Variety of Diols. J. Polym. Sci. Part A Polym. Chem. 2011, 49, 3759-3768. [CrossRef]

55. Papageorgiou, G.Z.; Tsanaktsis, V.; Bikiaris, D.N. Synthesis of Poly(Ethylene Furandicarboxylate) Polyester Using Monomers Derived from Renewable Resources: Thermal Behavior Comparison with PET and PEN. Phys. Chem. Chem. Phys. 2014, 16, 7946-7958. [CrossRef] [PubMed]

56. Knoop, R.J.I.; Vogelzang, W.; van Haveren, J.; van Es, D.S. High Molecular Weight Poly(Ethylene-2,5-Furanoate); Critical Aspects in Synthesis and Mechanical Property Determination. J. Polym. Sci. Part A Polym. Chem. 2013, 51, 4191-4199. [CrossRef]

57. Van Berkel, J.G.; Guigo, N.; Kolstad, J.J.; Sbirrazzuoli, N. Biaxial Orientation of Poly(ethylene 2,5-furandicarboxylate): An Explorative Study. Macromol. Mater. Eng. 2018, 303, 1700507. [CrossRef]

58. Araujo, C.F.; Nolasco, M.M.; Ribeiro-Claro, P.J.A.; Rudić, S.; Silvestre, A.J.D.; Vaz, P.D.; Sousa, A.F. Inside PEF: Chain Conformation and Dynamics in Crystalline and Amorphous Domains. Macromolecules 2018, 51, 3515-3526. [CrossRef]

59. Codou, A.; Guigo, N.; van Berkel, J.; de Jong, E.; Sbirrazzuoli, N. Non-Isothermal Crystallization Kinetics of Biobased Poly(Ethylene 2,5-Furandicarboxylate) Synthesized via the Direct Esterification Process. Macromol. Chem. Phys. 2014, 215, 2065-2074. [CrossRef]

60. Van Berkel, J.; de Jong, E.; Sbirrazzuoli, N. Modelling the Non-Isothermal Crystallization of Polymers: Application to Poly(Ethylene 2,5-Furandicarboxylate). Thermochim. Acta 2017, 650, 66-75. [CrossRef]

61. Codou, A.; Guigo, N.; Van Berkel, J.G.; De Jong, E.; Sbirrazzuoli, N. Preparation and characterization of poly(ethylene 2,5-furandicarboxylate/nanocrystalline cellulose composites via solvent casting. J. Polym. Eng. 2017, 37, 869-878. [CrossRef]

62. Yu, Z.; Zhou, J.; Cao, F.; Zhang, Q.; Huang, K.; Wei, P. Synthesis, Characterization and Thermal Properties of Bio-Based Poly(Ethylene 2,5-Furan Dicarboxylate). J. Macromol. Sci. Part B Phys. 2016, 55, 1135-1145. [CrossRef]

63. Stoclet, G.; Gobius Du Sart, G.; Yeniad, B.; De Vos, S.; Lefebvre, J.M. Isothermal crystallization and structural characterization of poly(ethylene-2,5-furanoate). Polymer 2015, 72, 165-176. [CrossRef]

64. Jiang, M.; Liu, Q.; Zhang, Q.; Ye, C.; Zhou, G. A Series of Furan-Aromatic Polyesters Synthesized via Direct Esterification Method Based on Renewable Resources. J. Polym. Sci. Part A. 2012, 50, 1026-1036. [CrossRef]

65. Rosenboom, J.-G.; Roo, J.D.; Storti, G.; Morbidelli, M. Diffusion (DOSY) 1H NMR as an Alternative Method for Molecular Weight Determination of Poly(ethylene furanoate) (PEF) Polyesters. Macromol. Chem. Phys. 2017, 218, 1600436. [CrossRef] 
66. Terzopoulou, Z.; Karakatsianopoulou, E.; Kasmi, N.; Tsanaktsis, V.; Nikolaidis, N.; Kostoglou, M.; Papageorgiou, G.Z.; Lambropoulou, D.A.; Bikiaris, D.A. Effect of catalyst type on molecular weight increase and coloration of poly(ethylene furanoate) biobased polyester during melt polycondensation. Polym. Chem. 2017, 8, 6895-6908. [CrossRef]

67. Hong, S.; Min, K.-D.; Nam, B.-U.; Park, O.O. High molecular weight bio furan-based co-polyesters for food packaging applications: Synthesis, characterization and solid-state polymerization. Green Chem. 2016, 18, 5142-5150. [CrossRef]

68. Sipos, L. A Process for Preparing a Polymer Having a 2,5-Furandicarboxylate Moiety within the Polymer Backbone and Such (Co)polymers. WO Patent 2010/077133 A1, 8 July 2010.

69. Achilias, D.S.; Chondroyiannis, A.; Nerantzaki, M.; Adam, K.-V.; Terzopoulou, Z.; Papageorgiou, G.Z.; Bikiaris, D.N. Solid State Polymerization of Poly(Ethylene Furanoate) and Its Nanocomposites with $\mathrm{SiO}_{2}$ and $\mathrm{TiO}_{2}$. Macromol. Mater. Eng. 2017, 302, 1700012. [CrossRef]

70. Kasmi, N.; Majdoub, M.; Papageorgiou, G.Z.; Achilias, D.S.; Bikiaris, D.N. Solid state polymerization of poly(ethylene furanoate) biobased polyester, I: Effect of catalyst type on molecular weight increase. Polymers 2017, 9, 607. [CrossRef]

71. Kasmi, N.; Papageorgiou, G.Z.; Achilias, D.S.; Bikiaris, D.N. Solid-State Polymerization of Poly (Ethylene Furanoate) Biobased Polyester, II: An Efficient and Facile Method to Synthesize High Molecular Weight Polyester Appropriate for Food Packaging Applications. Polymers 2018, 10, 471. [CrossRef]

72. Terzopoulou, Z.; Karakatsianopoulou, E.; Kasmi, N.; Majdoub, M.; Papageorgiou, G.Z.; Bikiaris, D.N. Effect of catalyst type on recyclability and decomposition mechanism of poly(ethylene furanoate) biobased polyester. J. Anal. Appl. Pyrolysis 2017, 126, 357-370. [CrossRef]

73. Berkowitz, S. Viscosity-molecular weight relationships for poly(ethylene terephthalate) in hexafluoroisopropanol-pentafluorophenol using SEC-LALLS. J. Appl. Polym. Sci. 1984, 29, 4353-4361. [CrossRef]

74. Karayannidis, G.P.; Kokkalas, D.E.; Bikiaris, D.N. Solid-state polycondensation of poly(ethylene terephthalate) recycled from postconsumer soft-drink bottles. I. J. Appl. Polym. Sci. 1993, 50, 2135-2142. [CrossRef]

75. Pohl, H.A. Determination of carboxyl end groups in a polyester, polyethylene terephthalate. Anal. Chem. 1954, 26, 1614-1616. [CrossRef]

76. Ravindranath, K.; Mashelkar, R.A. Modeling of Poly(ethylene Terephthalate) Reactors. I. A Semibatch Ester Interchange Reactor. J. Appl. Polym. Sci. 1981, 26, 3179-3204. [CrossRef]

77. Mallon, F.K.; Ray, W.H. Modeling of solid-state polycondensation. II. Reactor design issues. J. Appl. Polym. Sci. 1998, 69, 1775-1788. [CrossRef]

78. Ma, Y.; Agarwal, U.S.; Sikkema, D.J.; Lemstra, P.J. Solid-state polymerization of PET: Influence of nitrogen sweep and high vacuum. Polymer 2003, 44, 4085-4096. [CrossRef]

79. Ma, Y.; Agarwal, U.S. Solvent assisted post-polymerization of PET. Polymer 2005, 46, 5447-5455. [CrossRef]

80. Bikiaris, D.N.; Achilias, D.S.; Giliopoulos, D.J.; Karayannidis, G.P. Effect of activated carbon black nanoparticles on solid state polymerization of poly(ethylene terephthalate). Eur. Polym. J. 2006, 42, 3190-3201. [CrossRef]

81. Achilias, D.S.; Karandrea, E.; Triantafyllidis, K.S.; Ladavos, A.; Bikiaris, D.N. Effect of organoclays type on solid-state polymerization (SSP) of poly(ethylene terephthalate): Experimental and modelling. Eur. Polym. J. 2015, 63, 156-167. [CrossRef]

82. Achilias, D.S.; Gerakis, K.; Giliopoulos, D.J.; Triantafyllidis, K.S.; Bikiaris, D.N. Effect of high surface area mesoporous silica fillers (MCF and SBA-15) on solid state polymerization of PET. Eur. Polym. J. 2016, 81, 347-364. [CrossRef]

83. Lotti, N.; Munari, A.; Gigli, M.; Gazzano, M.; Tsanaktsis, V.; Bikiaris, D.N.; Papageorgiou, G.Z. Thermal and structural response of in situ prepared biobased poly(ethylene 2,5-furan dicarboxylate) nanocomposites. Polymer 2016, 103, 288-298. [CrossRef]

84. Maini, L.; Gigli, M.; Gazzano, M.; Lotti, N.; Bikiaris, D.N.; Papageorgiou, G.Z. Structural Investigation of Poly(ethylene furanoate) Polymorphs. Polymers 2018, 10, 296. [CrossRef]

85. Filgueiras, V.; Vouyiouka, S.N.; Papaspyrides, C.D.; Lima, E.L.; Pinto, J.C. Solid-state polymerization of poly(ethyleneterephthalate): The effect of water vapor in the carrier gas. Macromol. Mater. Eng. 2011, 296, 113-121. [CrossRef] 
86. Groeninckx, G.; Reynaers, H.; Berghmans, H.; Smets, G. Morphology and melting behavior of semicrystalline poly(ethylene terephthalate). I. Isothermally crystallized PET. J. Polym. Sci. Polym. Phys. Ed. 1980, 18, 1311-1324. [CrossRef]

87. Minakov, A.A.; Mordvintsev, D.A.; Schick, C. Melting and reorganization of poly(ethylene terephthalate) on fast heating $(1000 \mathrm{~K} / \mathrm{s})$. Polymer 2004, 45, 3755-3763. [CrossRef] 